\title{
Manipulación política y conflicto interno. La presencia insurgente en la zona Mixe Baja de Oaxaca, México, 1812-1818\%
}

\author{
Political manipulation and inside conflict. \\ The insurgent presence in Oaxaca's Mixe Baja zone, \\ Mexico, 1812-1818
}

\author{
Huemac Escalona Lüttig \\ Escuela de Estudios Hispano-Americanos de Sevilla \\ Universidad Pablo de Olavide
}

Este artículo analiza el comportamiento de tres pueblos mixes de las subdelegaciones de Nexapa y de Villa Alta (Mazatlán, Acatlán y Candayoc) ante la ocupación insurgente de la ciudad de Oaxaca a finales de 1812. Dada la carencia de estudios sobre este periodo en la región mixe, este trabajo es una primera aproximación para conocer la respuesta de los pueblos indígenas de esta área de Oaxaca, tanto a nivel local como regional, frente a la coyuntura política que significó el establecimiento de un gobierno insurgente entre 1812 y 1814 en la intendencia de Oaxaca.

Palabras Clave: Pueblos indígenas; Insurgencia; Oaxaca; Conflicto interno; Política local.

This article analyzes the behaviour of three mixe villages from Nexapa and Villa Alta subdelegations (Mazatlán, Acatlán y Candayoc) in the face of the insurgent occupation of Oaxaca's city at the end of 1812. Given that it doesn't exist studies about this period in the mixe region, this work is a first approach to know the indigenous villages response in this area of Oaxaca, both local and regional level, opposite the political juncture that brought the establishment of an insurgent govern in the Oaxaca's intendancy between 1812 and 1814.

KEYWORDS: Indigenous villages; Insurgency; Oaxaca; Inside conflict; Local policy.

* Agradezco a Irene Gómez Fernández por su valiosa ayuda en la corrección del texto, así como en la elaboración de los mapas. De igual manera expreso otro agradecimiento a los organizadores del 3rd International Conference of the Research Network for Latin America (Bielefeld, 2 al 3 de julio de 2012) por la aceptación de la ponencia que fue la base de este trabajo. 
La participación indígena en en la guerra de independencia de México (1810-1821) ha sido un tema tratado por varios autores desde distintas perspectivas que van desde los estudios de caso, regionales, comparativos entre regiones o pueblos, y los generales. Respecto a los primeros se destaca el trabajo de Marta Terán para la región de Michoacán y el de Carlos Sánchez Silva correspondiente a la de Oaxaca. ${ }^{1}$ Entre los segundos están las investigaciones de Juan Carlos Cortés sobre dos pueblos de Michoacán, ${ }^{2}$ Antonio Escobar para las huastecas, ${ }^{3}$ John Tutino sobre el valle del mezquital $^{4}$ y Francisco López Bárcenas ${ }^{5}$ y Margarita Menegus para la mixteca. ${ }^{6}$ Respecto a los trabajos comparativos remito a Taylor, que estudia los alrededores de Guadalajara y las zonas oaxaqueñas de la mixteca y el valle de Oaxaca, ${ }^{7}$ así como a Peter Guardino que se ocupa del ámbito urbano de la ciudad de Oaxaca y del rural indígena de la sierra Norte de Oaxaca. ${ }^{8}$ Entre los principales estudios con un enfoque general encontramos los de Manuel Ferrer Muñoz, ${ }^{9}$ Juan Ortiz Escamilla ${ }^{10}$ y Eric Van Young, quienes analizan el proceso de la lucha insurgente a partir de los sectores de la población novohispana que participaron en la contienda armada, destacando el grupo indígena por su elevado número de integrantes. ${ }^{11}$

Ante la falta de estudios históricos de otras regiones indígenas de Oaxaca que no sean las mixtecas y las zapotecas, ${ }^{12}$ me propuse hacer una primera aproximación a la historia mixe de finales del periodo colonial a partir del hallazgo de un expediente sobre un conflicto de tierras a comienzos del siglo XIX. ${ }^{13}$ En él aparecieron detalles que indicaban sucesos relacionados con la lucha por la independencia en la zona mixe. Con los datos obtenidos pretendo brindar un panorama de las acciones que protagonizaron, entre 1812 y 1814, tres pueblos mixes: San Juan Mazatlán, San Pedro

1 Terán, 2002; Sánchez Silva, 2012.

2 Cortés Máximo, 2007.

3 Escobar, 2002.

4 Tutino, 2002.

5 López Bárcenas, 2012.

6 Menegus, 2012a.

7 Taylor, 2008.

8 Guardino, 2009.

9 Ferrer Muñoz, 1999.

10 Ortiz Escamilla, 1997.

11 Van Young, 2006.

12 Actualmente existen 52 grupos indígenas en todo México, 15 de ellos se ubican en el estado de Oaxaca. Para más detalles sobre la población indígena actual de México, ver www.nacionmulti cultural.unam.mx 7 de octubre de 2012; y www.cdi.gob.mx 7 de octubre de 2012.

13 Archivo Histórico del Poder Judicial de Oaxaca (AHJO), Yautepec, Civil, 1813-1818, 6, 11. 
Acatlán y Jaltepec de Candayoc. Dos de ellos, Acatlán y Mazattlán se ubicaban en la subdelegación de Nexapa y el tercero, Candayoc, en la de Villa Alta. Así pues, el objetivo de este artículo es analizar las respuestas que tuvieron los pueblos indígenas mixes ante la ocupación de la intendencia de Oaxaca por Morelos y el establecimiento de un gobierno insurgente entre 1812 y 1814 . Me interesa conocer y mostrar las estrategias que estos pueblos o miembros de ellos implementaron para obtener ventajas tanto de los mandos insurgentes como de los realistas con el fin de favorecer sus intereses. Sugiero que una estrategia implementada por los indígenas fue la manipulación política de los representantes de los gobiernos instaurados por ambos mandos.

El análisis realizado sigue los planteamientos de Peter Guardino, Yana Yannakakis y María de los Ángeles Romero Frizzi sobre la cultura política de los indígenas en el período colonial. Guardino refiere la existencia de una cultura política corporativista en la Nueva España que incluía la diversidad local, en la que las reglas eran aplicadas a través de procesos que implicaban conflictos y negociaciones. ${ }^{14}$ Yannakakis señala la formación de una cultura política colonial a partir de la aplicación de un sistema legal que incluía procedimientos judiciales, transacciones legales y representaciones orales. Esta autora hace énfasis en que el procedimiento legal «ofrecía un terreno para la negociación de las relaciones de poder locales, que se podían reacomodar en función de las decisiones judiciales». ${ }^{15}$ Ambos especialistas advierten sobre la importancia de la micropolítica o política local como elemento medular del sistema colonial, donde los indígenas eran los principales protagonistas. Estos últimos, como ha señalado Romero Frizzi, usaron el derecho novohispano no sólo como una solicitud de justicia sino más bien como parte de una red de alianzas en búsqueda de poder. ${ }^{16}$

A continuación quiero aclarar el uso de algunas categorías o términos que aparecen a lo largo del presente trabajo. Utilizaré la categoría de «pueblo» de acuerdo al contexto colonial, en donde los asentamientos de indígenas eran reconocidos legalmente como entidades colectivas con derechos y obligaciones bajo la figura de «repúblicas de indios». Como lo señala Lenkersdorf, estas repúblicas «fueron organizadas después de que la pobla-

14 Guardino, 2009, 29.

15 Yannakakis, 2006, 840.

16 Romero Frizzi, 2004, 26. 
ción autóctona había sido reubicada en asentamientos urbanizados y adquirieron personalidad jurídica al ser regidas cada una por su cabildo indígena, es decir, un autogobierno de tipo municipal». ${ }^{17}$ Por otro lado, refiero el término «subdelegación» correspondiente a una demarcación administrativa creada a finales del siglo XVIII. Una vez implementadas las reformas borbónicas en el virreinato de la Nueva España con la intención de mejorar su administración, se dividió en intendencias y éstas, a su vez, en subdelegaciones. Las subdelegaciones contaban con un juez o subdelegado que: «Tenía la obligación de cumplir con las responsabilidades correspondientes a sus cargos, tales como, por ejemplo, la supervisión de los cabildos y las repúblicas de indios, la observancia de las leyes o la recaudación de impuestos, y además, difundir las nuevas disposiciones entre la población y hacerlas cumplir». ${ }^{18}$ En resumen, las funciones del subdelegado abarcaban las áreas de justicia, policía, hacienda y militar.

El texto está dividido en cuatro apartados: el primero trata el contexto de la ocupación por las tropas de Morelos de la provincia de Oaxaca entre 1812 y 1814; el segundo tiene como tema central lo ocurrido en la zona zapoteca de Villa Alta en los años de 1812 y 1813 - que como se verá guarda estrecha relación con los sucesos de Nexapa-, con un breve análisis de las diversas respuestas de algunos de los pueblos de aquella región ante la presencia de los insurgentes; el tercero aborda el caso de Mazatlán, donde de 1812 a 1814 tuvo lugar una lucha de facciones por el control político del gobierno local, en la cual uno de los grupos se declaró insurgente; y el cuarto analiza el impacto de la lucha insurgente en el alargamiento y solución de una disputa por tierras entre los pueblos vecinos de Acatlán y Candayoc, desde 1812 hasta 1818.

El territorio que abarcaban las subdelegaciones de Nexapa y Villa Alta era muy amplio, las dos jurisdicciones colindaban por el noreste con la subdelegación de Acayucán, perteneciente al actual estado de Veracruz. Nexapa y Villa Alta compartían una larga frontera en donde los límites entre una y otra se difuminaban a través de las montañas de la sierra mixe y la selva del Istmo de Tehuantepec (ver mapa I). Precisamente en esta porción colindante - que era la parte norte de Nexapa y sur de Villa Altaestaban localizados a principios del siglo XIX la mayoría de los pueblos mixes: treinta pertenecían a Villa Alta y catorce a Nexapa. ${ }^{19}$ Hoy en día,

17 Lenkersdorf, 2010, 14.

18 Hensel, 2009, 213-214.

19 Arrioja, 2008a, 591. 
MANIPULACIÓN POLÍTICA Y CONFLICTO INTERNO
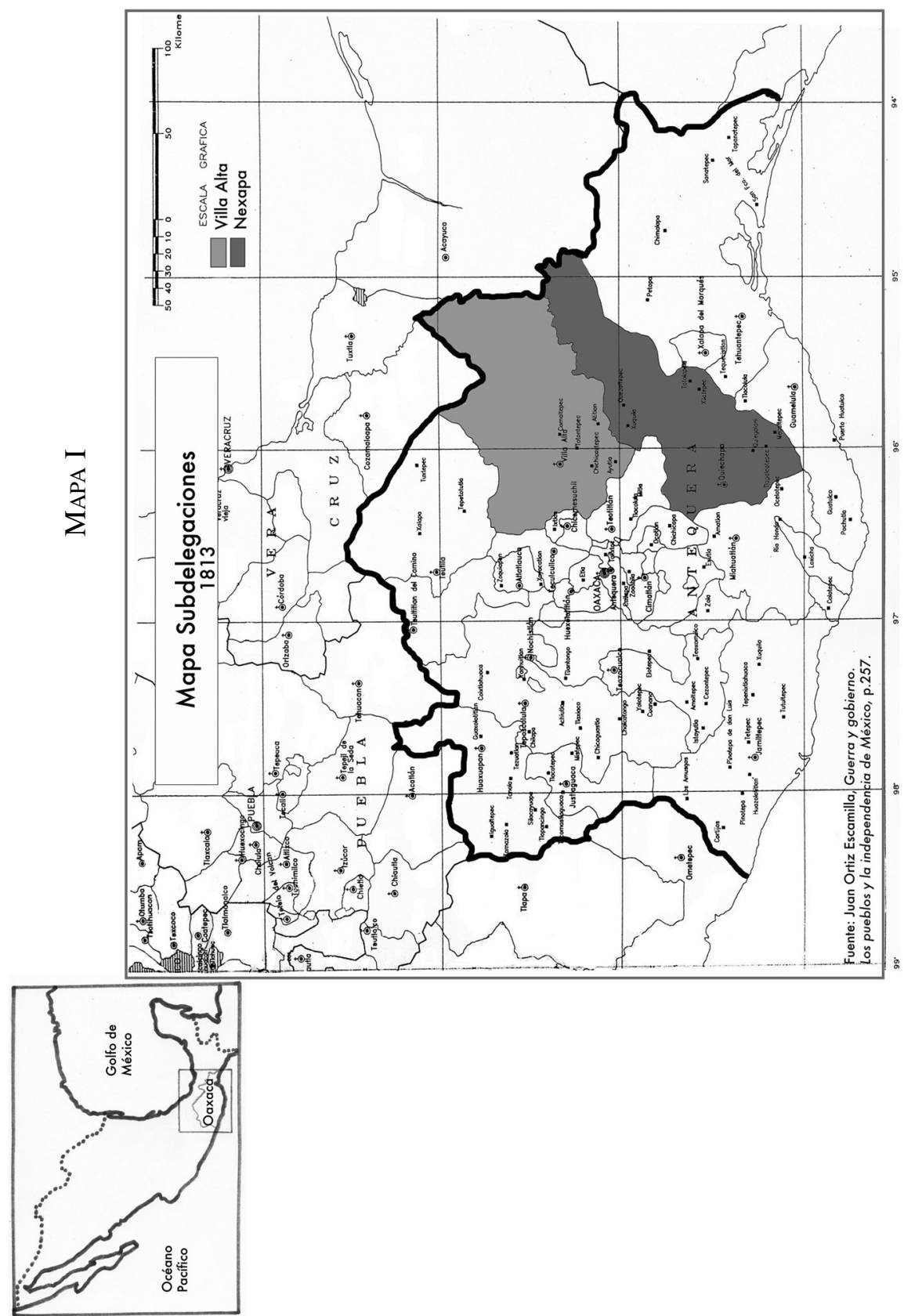
casi todos los pueblos mixes pertenecen al distrito mixe que forma parte del estado de Oaxaca. ${ }^{20}$

La geografía de la región mixe es abrupta y de grandes contrastes. Una parte de su territorio está compuesto por una sierra con montañas que llegan a los 3.000 metros sobre el nivel del mar, con un clima frío y lluvioso que se mantiene casi todo el año, aunque en sus barrancas se encuentran nichos con ecosistemas tropicales y temperaturas más cálidas. Otra parte corresponde a una zona intermedia entre las grandes montañas y las tierras bajas; en ella impera un clima cálido templado y la altitud promedio va de los 1.000 a los 2.000 metros sobre el nivel del mar. Una tercera porción que forma parte del Istmo de Tehuantepec la componen las tierras bajas de clima cálido-húmedo, donde las elevaciones máximas llegan a los 800 metros sobre el nivel del mar. Justamente, en la zona baja se encuentran los tres pueblos protagonistas de este trabajo: San Juan Mazatlán, San Pedro Acatlán y Jaltepec de Candayoc.

En la época colonial los mixes se dedicaban al cultivo de maíz, fríjol, chile pasilla, algodón y, en las zonas bajas, caña de azúcar. Algunos pueblos se especializaron en la producción de grana cochinilla y otros en el hilado y tejido de algodón para la fabricación de mantas. Hoy los pobladores de las tres comunidades son campesinos que cultivan maíz, fríjol, café y complementan sus ingresos con la fabricación de textiles bordados para su venta en la ciudad de Oaxaca. También aprovechan sus bosques de donde extraen maderas finas como el cedro.

\section{Los insurgentes en Oaxaca}

Una vez que el principal líder de la insurrección de 1810 contra el gobierno español, el cura Miguel Hidalgo, fuera ejecutado por los realistas, el mando de los insurgentes se concentró en la figura de otro clérigo de nombre José María Morelos. Éste desarrolló sus más importantes campañas militares en las regiones correspondientes a los actuales estados de Guerrero, Puebla, Morelos y Oaxaca. Morelos llegó a fines de noviembre de 1812 a la capital de lo que entonces era la intendencia de Oaxaca. Al mismo tiempo, en España se promulgaba la Constitución de Cádiz, la cual no llegó a proclamarse en Oaxaca ese año sino hasta 1814, después de la

20 El distrito mixe se compone de 17 de los 19 municipios mixes. Creado en 1938, es el único distrito judicial en la República Mexicana que tiene la adscripción de un solo grupo étnico (el ayuuk o mixe). Para más información, ver Nahmad, 2003. 
ocupación insurgente. ${ }^{21}$ Pero sólo estuvo vigente unos pocos meses debido a la vuelta al poder de Fernando VII, quien en mayo de ese mismo año la abolió para instaurarse como monarca absoluto. ${ }^{22}$

Las tropas insurgentes, previamente concentradas en Etla, en el valle de Oaxaca, derrotaron a las realistas que defendían la ciudad a finales de noviembre de 1812. El día 25 de ese mismo mes, Morelos y su ejército entraron a la ciudad de Oaxaca. Como resalta Hamnett, Oaxaca fue, desde que Hidalgo saliera de Guadalajara en enero de 1811, la primera capital de una provincia en caer bajo el dominio de las tropas insurgentes. Ocupada la ciudad, Morelos buscó controlar todo el territorio de la intendencia y para lograrlo distribuyó algunas de sus fuerzas por las regiones oaxaqueñas. A finales de 1812 mandó a los hermanos Víctor y Manuel Bravo hacia la costa en dirección a Jamiltepec, siguiendo el camino que pasaba por Juquila. ${ }^{23}$ Por su parte, Matamoros recibió órdenes de acercarse al Istmo de Tehuantepec en abril de 1813 para enfrentar a los realistas procedentes de Guatemala (ver mapa II) ${ }^{24}$ Gay refiere que Ramón Sesma fue enviado por Morelos a Villa Alta a comienzos de $1813 .{ }^{25}$ La zona de la mixteca alta y baja había sido frecuentada a lo largo de 1812 por los insurgentes y fue la ruta seguida por Morelos para la toma de la ciudad de Oaxaca. Para entonces, Morelos y sus tropas contaban con el apoyo de varios pueblos mixtecos. ${ }^{26}$

21 Sánchez Silva, 2008, y Mendoza, 2004, 21-24, señalan las dificultades que tuvieron el gobierno central y el provincial para llevar a cabo las modificaciones en Oaxaca que dictaba la constitución gaditana.

22 Guardino, 2009, 237. Sobre la aplicación de la Constitución de Cádiz en la Nueva España y sus efectos existe una bibliografía extensa. Algunos de los principales estudios son: Hernández Chávez, 1993; Annino, 1995; Ortiz Escamilla y Serrano, 2007; Salinas, Birrichaga y Escobar, 2011.

23 Bustamante 1961, I, 286 y 504-507, señala que en 1811 Antonio Valdés «dio el primer grito de insurrección que se oyó en la provincia de Oaxaca». Valdés lideró una fuerza insurgente conformada por indígenas de los pueblos de Jamiltepec, Pinotepa del Rey «y otros de la costa de Xicayán». A pesar de tener buen armamento fue derrotado en el cerro de Chacahua por el capitán de Tututepec, Juan Antonio Caldelas, el 19 de noviembre de ese año. Después relata la expedición de los hermanos Bravo a Jamiltepec.

24 Ibidem, 533-535.

25 Gay, 1978, II, 414.

26 De Bustamante 1961, I, 287, narra que Miguel Bravo «con tropas levantadas en la costa del Sur descendieron a la mixteca, en Yanhuitlán tuvieron su primer enfrentamiento con las tropas realistas el 9 de enero de 1812». Taylor, 2008, 208-209, señala que el apoyo de los pueblos de la mixteca a Morelos pudo ser motivado por la comercialización de la grana cochinilla, en la que salían desfavorecidos los indígenas, y la diferenciación de la población provocada por el acceso a tierras menos productivas. Ortiz Escamilla, 1997, 99 y 215, indica que los pueblos rebeldes entre 1811 y 1812 eran Yanhuitlán y San Cristóbal Amoltepec, ambos de la subdelegación de Teposcolula. También presenta una lista de los pueblos insurgentes de la subdelegación de Xicayán para las mismas fechas. El autor advierte que los pueblos de la mixteca entre 1812 y 1814 colaboraron tanto con los realistas como con los insurgentes para evitar saqueos y penas severas. 
Morelos estuvo poco tiempo en Oaxaca, pues a inicios de abril de 1813 se ubicó ya en los alrededores de Acapulco, ocupado en la toma del fuerte de San Diego, donde se habían atrincherado las tropas realistas de aquella ciudad. Este hecho desvió su atención y, sumado a la pérdida de Valladolid y a la mala gestión de sus compañeros Benito Rocha y Juan Moctezuma y Cortés, a cargo de la provincia de Oaxaca, ${ }^{27}$ ocasionó que esta última fuera recuperada para la causa realista el 29 de marzo de 1814 por el brigadier Melchor Álvarez. ${ }^{28}$

Frente a estos acontecimientos cabe preguntarse: ¿Qué estaba sucediendo por entonces en la zona de las subdelegaciones de Villa Alta y Nexapa? ¿Cómo reaccionaron los pueblos mixes pertenecientes a ambas jurisdicciones ante la cercanía de las tropas insurgentes? Estas y otras preguntas trataré de responder en los siguientes apartados.

\section{Villa Alta: curas y comerciantes realistas contra pueblos rebeldes}

En relación a Villa Alta, Guardino señala que no hay muchos documentos que detallen las actividades rebeldes y las reacciones de los habitantes de la jurisdicción de Villa Alta. Aun así, con los pocos datos obtenidos, este autor analiza algunas de las situaciones que quedaron registradas en los archivos oaxaqueños. Un ejemplo de ello es la carta del sacerdote del pueblo zapoteca de Yahuive, Joseph María de Paz y Mendoza, enviada en marzo de 1812 al virrey Francisco Javier Venegas, donde se mostraba el miedo que tenían los pocos habitantes españoles y criollos de la provincia - la mayoría de ellos funcionarios, sacerdotes y comerciantes- de una insurrección general. El cura de Yahuive acusó a sus feligreses de ser simpatizantes de los insurgentes y de manifestar intenciones de liberarse matando a los españoles europeos. En su misiva el párroco incluyó el texto de un pasquín, cuya autoría adjudicó a los jóvenes del pueblo. El texto incitaba a echar a los españoles y volver al tiempo de los indios con la ayu-

27 Gay, 1978, II, 412, relata que Morelos nombró a Benito Rocha comandante militar de Oaxaca el 9 de febrero en 1813. En noviembre de ese año Rocha se trasladó a Tehuacán y dejó en el cargo de manera interina a Juan Moctezuma. En marzo volvería Rocha a Oaxaca pero solo para organizar la retirada insurgente de la ciudad. Sobre el papel desafortunado de Juan Moctezuma como gobernador interino de Oaxaca y su peculiar historia personal, ver Cruz Pazos, 2011. Para mayor información sobre la ocupación y el gobierno insurgente de la ciudad y provincia de Oaxaca entre 1812 y 1814 , ver Hamnett. 1978, 168-179, y Guardino, 2009, 212-230.

28 Hamnett, 2010, 207-209. 
da de los insurgentes. Pero detrás de la denuncia contra los supuestos rebeldes había un conflicto entre el cura y los habitantes del pueblo por el pago de los servicios religiosos..$^{29}$ A pesar de las amenazas contra el cura, no hay datos que indiquen que Yahuive apoyó abiertamente a los insurgentes cuando éstos se presentaron en su territorio, sino que, por el contrario, pareciera que se mantuvieron del lado realista como se verá más adelante.

Los temores de los no indios y las esperanzas de amplios sectores de la población nativa se materializaron cuando unos meses antes de la toma de Oaxaca, en julio de 1812, apareció un grupo insurgente en el pueblo de Yaveo, de la jurisdicción de Villa Alta. El día 31 de ese mes tuvo lugar un enfrentamiento entre dicho grupo y una partida de cuarenta realistas de la villa de Antequera. La fuerza rebelde estaba compuesta por «300 negros de la costa». Para fortuna de los no indios, los realistas obtuvieron el triunfo y dispersaron a los «rebeldes», poniendo así «en quietud a siete pueblos de aquella cordillera», según testimonio del capitán José Joaquín Arias que comandaba dicha partida. ${ }^{30}$

Guardino refiere que la fuerza rebelde derrotada en Yaveo había sido «aparentemente invitada por las autoridades del pueblo de Jalahui». El grupo insurgente estaba compuesto por mulatos de la costa de Veracruz y por mixes de la zona baja de la jurisdicción de Villa Alta. El mismo autor describe sus principales acciones antes de que llegaran los realistas del capitán Arias. Señala que, en un punto cercano al pueblo de Jalahui, los insurgentes se encontraron con los residentes y autoridades de dicho pueblo y con los de Latani, Santiago Sochiapan y otros más de la zona de Choapan. Una vez reunidos se apropiaron de una caravana de mulas con bienes de «españoles europeos y capturaron a sus dueños y arrieros». Acto seguido celebraron las detenciones con música, bailes y bebida. Días después, otra caravana fue interceptada en el pueblo de Solaga por una multitud de indígenas al mando del mayor de dicho pueblo, Antonio Matías. ${ }^{31}$ Después de someter a los arrieros, se llevaron la carga y metieron en la cárcel al comerciante y a sus mozos. Por su parte, Pedro Flores, indígena de Jalahui y líder insurgente, atacó con sus tropas el pueblo de Zoochila, «que había desafiado su orden bajo influencia de su sacerdote residente, Francisco María Ramírez». ${ }^{32}$

29 Guardino, 2009, 231-232.

30 Archivo General del Estado de Oaxaca (AGEO), Guerra, 1814-1820, 37.

31 El mayor era un cargo de la república de indios en pueblos de la jurisdicción de Villa Alta en la época colonial. Arrioja, 2008a, 188.

32 Guardino, 2009, 232. 
Poco después de estos sucesos, la partida realista del capitán Arias llegó al área y en breve tiempo logró echar a las fuerzas insurgentes. En represalia a la participación abierta de Jalahui, el intendente de Oaxaca ordenó que saquearan y quemaran el pueblo por completo y que todas sus tierras se adjudicaran a Santa María Yahuive, que se había mantenido fiel a los realistas. ${ }^{33}$ Llegados a este punto, cabe preguntarse ¿por qué Yahuive permaneció fiel a los realistas cuando por lo menos un sector de la población se había manifestado abiertamente a favor de los insurgentes? Al carecer de más datos que brinden los detalles, sugiero que pudo existir una rivalidad entre los dos pueblos: el de Yahuive y el de Jalahui. Quizás, como consecuencia del involucramiento de Jalahui y del resultado adverso que a corto plazo tuvieron los insurgentes, Yahuive se mantuvo en un principio al margen de los acontecimientos y, después, una vez que la fuerza realista hizo presencia y tomó el control de la situación, manifestaron su apoyo a estos últimos. De esta forma podrían haber sacado cierta ventaja sobre el pueblo rival que se tradujera en la apropiación de sus tierras. Otra explicación probable es que el grupo a favor de los insurgentes que había en Yahuive fuera minoritario o tuviera poca influencia en el resto de la población. Si, como manifestó el cura de dicho pueblo, quienes hicieron el pasquín que incitaba a unirse a los insurgentes era un grupo de jóvenes, éstos pudieron haber sido reprimidos o maniatados por las autoridades del pueblo para que no trascendieran sus acciones.

Guardino refiere que el capitán y comerciante vasco Nicolás Aristi tomó el mando de una milicia realista de Villa Alta y se encargó de buscar y ejecutar a algunos líderes rebeldes que habían huido. Se tiene noticia de la existencia de otra fuerza realista en el pueblo de Santa María Puxmetacán al mando del comandante Calixto Pérez, pero no se sabe cuándo se formó y si tuvo alguna participación en las acciones llevadas a cabo por las otras fuerzas realistas en la jurisdicción. ${ }^{34}$ Por su parte, Nicolás de Aristi advirtió a la población de la jurisdicción que era su obligación encarcelar a cualquier indígena o forastero que no tuviera consigo un pase firmado por él. Aristi aprovechó la situación en favor de sus intereses, presionando a los pueblos para que le pagaran la grana cochinilla que había perdido en manos de los insurgentes. De igual forma, nombró nuevas autoridades en los pue-

33 Arrioja, 2008a, 318.

34 AGEO, Real Intendencia, Subdelegación Nexapa-Quiechapa, 1814-1815, 81, 42. Ortiz Escamilla, 1997, 196, refiere la existencia de una compañía de infantería en la zona de los mixes altos compuesta de cien efectivos; es probable que correspondiera a la de Calixto Pérez. 
blos, que recayeron en personas recomendadas por sus contactos comerciales. Estas intervenciones irritaron al subdelegado en turno, Julián Nieto Posadillo, quien se quejó ante el intendente de que Aristi estaba usurpando sus poderes. El gobierno real apoyó al subdelegado y en noviembre de 1812 reprimió a Aristi. Unas semanas después, ya en Oaxaca, durante la ocupación insurgente, Nicolás de Aristi moría fusilado junto con otros oficiales realistas..$^{35}$ Bustamante refiere que Aristi había ido a Villa Alta a «contener un tumulto» y que ahí los indios lo hicieron preso y lo entregaron a Morelos. Comenta que «merecía vivir» pero, como había «repartido a los indios», tenía enemigos que procuraron vengarse de él. ${ }^{36}$

Arrioja menciona un conflicto que tuvo Nicolas de Aristi con el pueblo de San Pedro Cajonos por un préstamo de 200 pesos, en donde el gobernador de dicho pueblo fue encarcelado durante cuatro meses hasta que los pobladores cubrieron la deuda. Aristi había presionado al subdelegado en turno para que el pueblo pagara la deuda a pesar de que sus pobladores se encontraban en la miseria. Era conocida en Villa Alta su fama de lograr que las autoridades de los pueblos que eran deudores de sus repartimientos fueran a la cárcel si no pagaban a tiempo. ${ }^{37}$ En este caso, los indígenas aprovecharon la coyuntura para deshacerse de Nicolás de Aristi y aliviar así la presión que este personaje ejercía sobre sus pueblos y sus habitantes.

No obstante la rápida derrota de las primeras fuerzas insurgentes en Villa Alta por parte de los realistas, cuatro meses después, estando los insurgentes establecidos en la ciudad de Oaxaca, Morelos renovaba la presencia rebelde en aquella zona al enviar una partida al mando de Ramón Sesma..$^{38}$ No sabemos los detalles de sus acciones; solo consta que su estancia en la jurisdicción no fue prolongada. Gay refiere que para finales de 1813 penetró por la zona de Betaza y Zoochila una partida de realistas al mando del subteniente Juan Murillo. Iba en persecución de Pedro Flores, quien se había refugiado en Villa Alta después de haber sido derrotado en

35 Guardino, 2009, 233. Hamnett, 1971, 135, señala que Nicolás de Aristi, que había sido subdelegado de Villa Alta, fue fusilado por las tropas de Morelos cuando éstas entraron en Oaxaca a finales de noviembre de 1812 .

36 De Bustamante, 1961, I, 495.

37 Arrioja, 2008a, 559.

38 Gay, 1978, 414, indica que Sesma fue enviado por Morelos a Villa Alta, pero no aporta mayores detalles. En agosto de 1813, Juan Francisco de Barberana aparecía como representante de la subdelegación de Villa Alta en la votación de representantes al congreso de Chilpancingo. Hernández Dávalos, 2008, IV, 1. 
Tuxtepec junto con otro grupo de insurgentes. Las tropas de Murillo fueron bien recibidas por los pueblos de Betaza y Comaltepec, distinguiéndose en los agasajos los curas de dichos pueblos ${ }^{39}$ Flores fue apresado en Villa Alta con la ayuda de la población local y fusilado ahí mismo. ${ }^{40}$

Por otro lado, en 1814, los habitantes de San Bartolomé Zoogocho y de Santiago Zoochila fueron acusados de haber respaldado a los insurgentes y en consecuencia las autoridades realistas les decomisaron los bienes que tenían resguardados en sus cajas de comunidad. ${ }^{41}$ Una vez que los realistas recuperaron la capital de la intendencia de Oaxaca, también lograron mantener el control de la mayor parte de la jurisdicción de Villa Alta, exceptuando la porción que colindaba con el actual estado de Veracruz.

En resumidas cuentas, entre 1812 y 1813 , la zona villalteca se vio sacudida por las incursiones de grupos insurgentes y realistas, algunos procedentes tanto de Veracruz como del valle de Oaxaca y otros formados en los mismos pueblos de la jurisdicción. Todos ellos recibieron apoyo de algún sector de la población de la zona en diversas formas y momentos. Así, por ejemplo, hay casos de párrocos que incidieron en que algunas comunidades se decantaran por el bando realista..$^{42}$ Otros pueblos se aliaron con los insurgentes por conflictos con comerciantes y curas identificados con los realistas y que habían sido abusivos en tratos establecidos con algunas comunidades indígenas. Sin embargo, además de lo señalado en este apartado, hubo otras circunstancias relacionadas con dinámicas locales que también influyeron para que los indígenas de Oaxaca respaldaran alguna de las partes o que, por lo menos, tuvieran un discurso que las posicionaba en uno de los dos bandos. ${ }^{43}$ Más adelante se retomará el tema a propósito de los sucesos que tuvieron lugar en los límites entre las jurisdicciones de Villa Alta y Nexapa.

39 Gay, 1978, 438. Se menciona también el pueblo de Zoochila, si bien - -junto con el de Zoogocho- fue acusado en 1814 de apoyar a los insurgentes. Ver Arrioja, 2008a, 318.

40 Gay, 1978, 438.

41 Arrioja, 2008a, 318.

42 Como ya indicó Ferrer, 1999, 526, el influjo de los curas sobre los feligreses en algunas regiones pudo condicionar la postura favorable u hostil de éstos hacia los insurgentes. En la nota 48 de su artículo menciona el caso del pueblo de Quiatoni, de la jurisdicción de Teotitlán, cuyo cura relató lo ocurrido cuando pasó por esa localidad el presbítero insurgente José Antonio Herrero: «fue bien visto y recibido de mis indios, dejándolos desengañados del error que padecían y quedando adictos a la justa causa y defensa de la religión a favor de la nación americana».

43 Taylor refiere un caso similar sobre la participación de los mixtecos, ver nota 26. 


\section{Nexapa: San Juan Mazatlán y la lucha de facciones}

$\mathrm{Al}$ igual que en el caso de la subdelegación de Villa Alta, la información respecto a Nexapa y la presencia insurgente entre 1812 y 1814 no es abundante. Aun así, se puede afirmar con los pocos datos encontrados que la llegada de Morelos a Oaxaca sí tuvo consecuencias en la jurisdicción. La documentación refiere la presencia de un capitán insurgente en la zona de los mixes bajos cuyo nombre era Rafael Gallardo. Son pocas las referencias sobre el origen y formación del grupo rebelde dirigido por Gallardo. No se sabe si se unió a las fuerzas de Morelos cuando este entró en la ciudad de Oaxaca, si lo hizo aprovechando la expedición de Matamoros a Tehuantepec en abril de 1813 o si fue parte del grupo de mixes que se incorporó a las fuerzas de Pedro Flores en Jalahui. Esto último es lo más probable debido a que algunos de sus hombres participaron en la detención de Nicolás de Aristi, en 1812, llevada a cabo en Villa Alta. ${ }^{44}$ En todo caso, las fuentes reflejan que la milicia de Gallardo se estableció entre 1812 y 1814 en el pueblo de San Juan Mazatlán de donde era originario. Desde ahí mantuvo en tensión la zona mixe baja que comprendía pueblos de las jurisdicciones de Nexapa (San Juan Mazatlán, Santiago Tutla, Santiago Malacatepec y San Pedro Acatlán) y de Villa Alta (Santa María Puxmetacán, San Juan Jaltepec de Candayoc y Ozolotepec). Su contraparte en el área fue el capitán realista Calixto Pérez, quien dirigía una milicia que tenía su base en Puxmetacán. ${ }^{45}$ No se tienen referencias alusivas a enfrentamientos directos entre ambos grupos. Lo que sí consta es que en las dos fuerzas había un número importante de indígenas mixes.

A lo largo de 1812 y 1813, la tropa del capitán Gallardo recorrió el territorio entre Villa Alta, San Juan Mazatlán y Tehuantepec (ver mapa II). Pero, a comienzos de 1814, cuando las tropas independentistas abandonaron la ciudad de Oaxaca, Gallardo también se retiró de la zona mixe baja. Una vez que éste salió de Mazatlán, sin noticia de cuál fue su destino final, dos grupos de pobladores se acusaron mutuamente de haber sido insurgentes. El caso del grupo insurgente de Rafael Gallardo en Mazatlán, junto con el de Pedro Flores en Jalahui, nos remite a la propuesta de Eric Van Young. Este autor plantea que, durante la guerra de independencia, los indígenas

44 AGEO, Real Intendencia, Subdelegación Nexapa-Quiechapa, 1814-1815, 81, 42.

45 Sobre la formación de la milicia de Puxmetacán, ver nota 34. Contamos con más información sobre la fuerza insurgente de Mazatlán que de los realistas. 
HUEMAC ESCALONA LÜTTIG

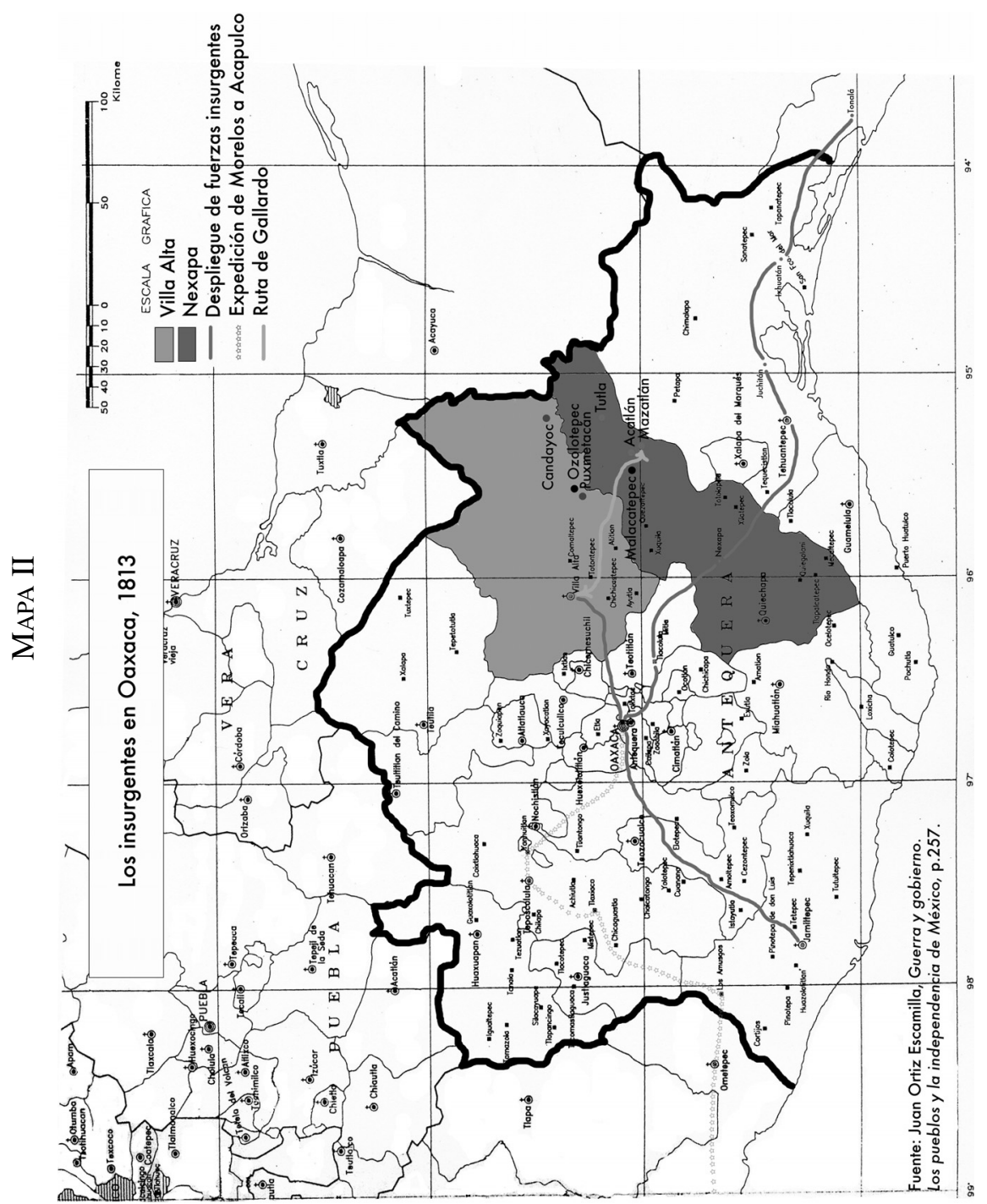


permanecieron muy cerca de sus pueblos, «al parecer demasiado ocupados en recuperar el equilibrio de las relaciones sociales, en ajustar viejas cuentas y protegiendo la integridad comunitaria». Señala también «que la incorporación a la causa rebelde generalmente siguiera líneas de parentesco, amistad, relaciones y lugar de residencia». ${ }^{46}$

Los pocos detalles que se conocen sobre el grupo de Gallardo provienen de cartas escritas por el subdelegado de Nexapa, José Román Ponze de León, al brigadier Melchor Álvarez cuando este recuperó para la causa realista la capital de la intendencia en marzo de 1814. Después de la salida insurgente de la ciudad de Oaxaca, Ponze de León fue objeto de cuestionamientos por rumores de haber estado a favor de los «insurrectos». ${ }^{47} \mathrm{~A}$ través de estas averiguaciones, así como de las declaraciones y confesiones de los indígenas acusados de rebeldes, salen a la luz los acontecimientos relacionados con la presencia de insurgentes en Mazatlán y en otros pueblos mixes de la jurisdicción de Nexapa como San Pedro Acatlán, Santiago Malacatepec y Santiago Tutla. ${ }^{48}$

46 Van Young, 2006, 265. Sobre la división interna de los pueblos entre facciones insurgentes y realistas, ver Ferrer, 1999, 528.

47 AGEO, Real Intendencia, Subdelegación Nexapa-Quiechapa, 1814-1815, 81, 42. Varios funcionarios de la Corona estuvieron bajo sospecha de simpatizar con los insurgentes antes y después de la ocupación de la intendencia de Oaxaca. Entre los presos que fueron liberados por los insurgentes cuando ocuparon la ciudad de Oaxaca estaba el subdelegado de Zimatlán, Carlos Enrique del Castillo. De Bustamante, 1961, I, 495. Otro caso es el del administrador y contador de la Real Aduana de Tehuantepec, que fue acusado por el subdelegado de aquella jurisdicción de ser «infidente» en 1812 , ver Archivo General de la Nación de México (AGN), Infidencias, 175, 83. Guardino, 2009, 212-217, da cuenta del ambiente tenso que hubo en la capital de la intendencia a partir de 1809. Tensión que se fue incrementando hasta la víspera de la entrada a la ciudad de Oaxaca de los insurgentes en 1812 y a la salida de los mismos en 1814. Esta situación de temores, sospechas y conspiraciones provocó una serie de ejecuciones y detenciones que involucraron a sacerdotes y autoridades civiles, principalmente criollos, tales como subdelegados y administradores de los ramos de la hacienda colonial. Desde 1809 hasta 1821, se realizó una estrecha vigilancia y control de la población de la Nueva España. Dicha función estuvo a cargo de la Junta de Seguridad y Buen Orden, de la que dependían las juntas provinciales como la de la intendencia de Oaxaca. Esta última recibió el nombre de Junta Auxiliar de Buen Orden. Para más detalles, ver Ibarra, 1995.

48 Los cuatro pueblos pertenecían a la misma parroquia; desde 1778 la cabecera de la misma era el pueblo de Acatlán. Esparza, 1994, 23. En el siglo XVIII, la mayoría de los pueblos indígenas de Oaxaca estaban organizados en varias categorías, entre las que se encontraban los pueblos cabecera y los pueblos sujetos. Romero Frizzi, 2011, 70, señala que: «Los españoles decidieron llamar a los asentamientos de más poder cabeceras, y a los de menor poder sujetos». Arrioja, 2008a, 171-172, hace una descripción más detallada de la organización jerárquica de los pueblos indios en la época colonial: «Las cabeceras representaban el polo de una jurisdicción ejercida sobre los habitantes de cierto territorio. No se trataba de unidades agrarias, ya que no regían la tenencia de la tierra; sin embargo, por el control que ejercían sobre la población, representaban una unidad territorial; también precisaban el centro o alguna subdivisión preponderante del pueblo respecto a sus componentes, que -a su vez- quedaban englo- 
El 25 de septiembre de 1814, José Román Ponze de León requirió por carta al gobernador de Mazatlán que se presentaran ante su juzgado cinco personas de ese pueblo denunciadas por amenazas y vejaciones. La parte acusadora la formaban Calixto José y Jacobo Santiago, originarios del mismo pueblo. Estos últimos estaban arrestados en Quiechapa, donde residía el subdelegado de Nexapa, bajo investigación por haber sido insurgentes. Los cinco demandados eran Nicolás Pacheco, Roque Servando, Manuel Gallardo ${ }^{49}$ Mariano Santiago e Isidro Mariano. El juez mandaba que vinieran acompañados por el gobernador del pueblo para que se carearan con los otros dos que tenía presos.

Sin embargo, Nicolás Pacheco y sus cuatro compañeros no se presentaron en el juzgado de Quiechapa, aunque sí mandaron una carta al intendente de Oaxaca a principios de noviembre de 1814 con su versión de los hechos. En su misiva alegaban ser inocentes y víctimas de los insurgentes. Pacheco explicó que él y los demás habían huido a los montes y barrancas durante siete meses cuando el capitán insurgente Rafael Gallardo entró a su pueblo y que tres de ellos fueron apresados por personas de su mismo pueblo que estaban «insurgentados». A través de un pago en reales pidieron que los liberaran, lo que ocurrió cuando entregaron 6 pesos (48 reales) a Gallardo. Señalaron que este último era nativo del mismo pueblo de Mazatlán y que los obligó a unirse a su grupo. No obstante lo anterior, Nicolás Pacheco y sus cuatro compañeros dijeron que, a pesar de haber pagado para que los liberaran, uno de ellos (Isidro Mariano) fue enviado a la cárcel de Tehuantepec, donde estuvo tres meses, y luego lo llevaron de regreso a Mazatlán, obligándolo también a «estar a sus armas», es decir, a rebelarse contra los realistas. Más tarde, siendo parte de la fuerza insurgente, huyeron por segunda vez, pero los volvieron a atrapar y sufragaron otros 9 pesos al capitán Gallardo para que los «liberara». A pesar de haber pagado por su «liberación», fueron obligados de nuevo a formar parte del grupo rebelde y al poco tiempo hicieron una tercera fuga, otra vez a los montes y barrancas, pero volvieron a ser apresados y llevados a la cárcel de la

bados en los términos de cabeceras dependientes y sujetos; además, las cabeceras eran sede del gobierno indígena, de las cajas de comunidad, de las autoridades nativas, de los ministros de culto y del grueso de la población.[...] Los sujetos por su parte agrupaban a pobladores que -geográficamente- estaban alejados de las cabeceras, pero ligados a ellas por vínculos políticos y fiscales; además, los sujetos eran asentamientos dependientes que prestaban servicios a las cabeceras. En este mismo orden, las autoridades coloniales empleaban las nomenclatura de cabeceras y sujetos para distinguir la circunscripción eclesiástica de las parroquias».

49 Posible familiar del capitán insurgente Rafael Gallardo. 
que «salieron pagando en reales». Bastante dinero tuvieron que abonar al capitán Gallardo por cada una de las fugas. Finalmente, dijeron que los insurgentes los liberaron por estar cerca los realistas y a los ocho días fue «redimido su pueblo». Para entonces, según Nicolás Pacheco, el capitán Gallardo había abandonado Mazatlán junto con su sargento Calixto José y Jacobo Santiago. ${ }^{50}$

En otra parte de su escrito, los acusados refieren que, al llegar la tropa española, la auxiliaron con víveres y se unieron al grupo del capitáncomandante de Puxmetacán, Calixto Pérez, a cuya partida dijeron pertenecer incluso antes de ser apresados por los insurgentes. Insistieron en que los sacerdotes de los pueblos vecinos de Quetzaltepec y Puxmetacán, Manuel Pedro Aubray y Juan José Mora respectivamente, estando en ese momento en la ciudad de Oaxaca, testificarían a su favor. ${ }^{51}$

Refirieron que el propio comandante de Puxmetacán, Calixto Pérez, podía confirmar su versión pues a éste le constaba que el «citado sargento [Calixto Pérez] con su soldado [Jacobo Santiago] fueron de los que acompañaron al capitán Gallardo tanto para hacer las iniquidades como los que ocurrieron a la prisión del [ya difunto] capitán Nicolás de Aristi». Dijeron que el comandante de Puxmetacán mandó al gobernador de Mazatlán que apresaran a Calixto José y Jacobo Santiago, «pero que como el gobernador y el alcalde Manuel Agustín son primos hermanos del indicado Calixto José», no lo habían hecho. Por último, señalaron que los citados Calixto José y Jacobo Santiago vociferaron que el subdelegado de Nexapa les había dicho que «el cura Morelos estaba en guerra y que no se acababa y que quién sabe quién ganaría». Que eso lo había escuchado Juan Pérez, indio de Candayoc, el cual estaba por accidente en Quiechapa y que «se dice por aquellos pueblos comarcanos el que [el intendente] Melchor Álvarez fue a la mixteca y se restituyó con una pierna rota, lo que hacemos presente por lo que ocurra». ${ }^{52}$

50 AGEO, Real Intendencia, Subdelegación Nexapa-Quiechapa, 1814-1815, 81, 42.

51 Idem.

52 AGEO, Real Intendencia, Subdelegación Nexapa-Quiechapa, 1814-1815, 81, 42. De Bustamante, 1961, II, 219 y 231, da cuenta de un enfrentamiento en Silacayoapan el 27 de julio de 1814 entre la tropa de Melchor Álvarez y una fuerza insurgente dirigida por Ramón Sesma, que se había pertrechado en dicho pueblo. Los realistas no pudieron derrotar a los rebeldes, quienes lograron romper el cerco el 19 de agosto de 1814. Bustamante no menciona que Melchor Álvarez fuera herido en esa ocasión; sí lo refiere en el caso de otra batalla en Teotitlán del Camino, el 12 de octubre de 1815, frente a las tropas de los hermanos Terán. El mismo autor narra que había un rumor de que Álvarez había sido herido de un brazo, aunque manifestó no tener la certeza de este hecho. Sobre las funciones del rumor en relación a la cultura verbal de la «guerra interna» y las cadenas de comunicación oral, ver Van Young, 2006, 582-592, y Guardino, 2009, 26-27. 
Existe otra explicación de los hechos según el subdelegado de Nexapa, quien ante todo trató de reafirmar su postura realista y desmentir los rumores de estar a favor de los insurgentes. Ponze de León recibió una copia del escrito con el testimonio de Nicolás Pacheco y sus compañeros con fecha del 11 de noviembre de 1814. A continuación respondió al comandante e intendente de Oaxaca aportando más detalles que ayudan a entender lo ocurrido en Mazatlán entre 1812 y 1814.

El subdelegado dijo que se habían presentado en su juzgado Calixto José, Jacobo Santiago y Lucas Antonio (en representación de su hijo, que por estar enfermo permaneció en el pueblo de Mazatlán). Éstos le contaron que Nicolás Pacheco, Roque Sebastián, Mariano Santiago, Isidro Mariano y Manuel Gallardo trataron de aprehenderlos por «habérselos llevado Rafael Gallardo por el rumbo de Villa Alta obligados de la misma fuerza con que los hizo entrar al servicio de las armas insurgentes». Refirieron que se habían fugado «del lado de Gallardo que se extendió hasta unirse con los rebeldes emigrados de la capital poco antes de llegar las tropas de Nuestro Soberano». Ponze de León refirió que, a principios de agosto de 1814, Calixto José, por temor a la amenaza de Pacheco y su grupo, se había presentado en Oaxaca para acogerse al indulto. Señaló que no le parecía raro lo que contaba Calixto José, pues era común «entre los indios el vicio de la venganza». Además, había comprobado la existencia del indulto de Calixto José que había sido expedido por el comandante interino, José Frances Enríquez, en ausencia de Melchor Álvarez..$^{53}$ Por otra parte, enfatizó que permitió que Jacobo Santiago y Lucas Antonio volvieran a su pueblo (Mazatlán) una vez que tuvo conocimiento de que el intendente Melchor Álvarez había recibido a los gobernadores de Tutla, Mazatlán y Acatlán, acusados de colaborar con los rebeldes, y que había absuelto a los dos primeros pueblos. Apuntó que, antes de irse, Jacobo Santiago y Lucas Antonio dieron su palabra de que comparecerían de nuevo en dicho juzgado cuando Pacheco y compañía lo hicieran también.

53 Como lo señalamos antes, entre el 27 de julio y el 19 de agosto, Melchor Álvarez dirigió el sitio al pueblo de Silacayoapan, donde se había fortificado el líder insurgente Ramón Sesma. De Bustamente, 1961, II, 218-219. Por otro lado, varios insurgentes de la zona se indultaron en diversos momentos de la contienda, como, por ejemplo, Antonio Isidro, insurgente de San Juan Guichicovi, que lo hizo en 1817, ver AGN, Infidencias, 175, 183. Otro caso es el del cura de Huamelula, José Mariano Dolores Gutiérrez, indultado en 1814, ver AGN, Infidencias, 109, 1 y 2. Para más información sobre los indultos durante la guerra de independencia, ver Ortiz Escamilla, 1997, 127, y Hamnett, 2010, 201 y 206. 
Ponze de León señaló que no podía certificar que Pacheco y sus compañeros hubieran huido a los montes y permanecido ahí meses, pero por informes que había obtenido sospechaba que éstos dieron alguna gratificación para ganar la voluntad al comandante de Puxmetacán. Que sólo cuando se vieron sin partido favorable ocurrieron al tribunal de Oaxaca y no antes. Acto seguido cuestionó que «¿cómo que no se hacen cargo [Pacheco y sus compañeros] en su escrito del delito de haber hecho armas para sus alcaldes? ¿cómo no confesaban haber dicho voz en grito que tan insurgentes eran mis alcaldes de Mazatlán como su subdelegado, su cura y aún el mío [se refiere al cura de Quiechapa] con otras muchas cosas?». Agregó, para desacreditar la denuncia de los indígenas en su contra, que «blasonan los representantes [de los pueblos] de leales y los indios son de la naturaleza de los huevos, que aquel que tiene conocimiento de uno, ya los conoce perfectamente a todos»..$^{54}$

Sobre el testimonio que pudieran presentar los mencionados curas de Puxmetacán y Quetzaltepec, el subdelegado expresa que no duda de la honradez de ambos pero éstos sólo podrían certificar que tanto Nicolás Pacheco como sus compañeros únicamente «parecen ser buenos patriotas», puesto que «los interiores sentimientos jamás los ha juzgado la iglesia». Por otro lado, cuestiona la autoridad del comandante de Puxmetacán sobre sus «súbditos» y el haber ignorado la suya al no enviar a su juzgado a los indígenas que había apresado pertenecientes a su jurisdicción. De igual forma señala la desobediencia del gobernador y alcaldes de Mazatlán de no efectuar la orden de remitirle a Nicolás Pacheco y sus compañeros. Cabe señalar en este punto que, frente a la confusión generada por las idas y venidas de los grupos realistas e insurgentes por el territorio de las subdelegaciones de Nexapa y Villa Alta y la consecuente inestabilidad política, así como la constante propagación de rumores, los indígenas involucrados en la lucha insurgente aprovecharon las contradicciones entre las distintas autoridades para librarse de ser castigados.

En la última parte de su escrito, el subdelegado de Nexapa se defendió de las acusaciones contra él, hechas por Nicolás Pacheco y sus compañeros, señalando su simpatía hacia los «insurrectos» a raíz de haber declarado que «Morelos estaba en guerra y quien sabe quien la ganaría». Ponze de León expresó que «apenas y hablaba con los indios» fuera de los asuntos del juzgado y «menos con los mixes». Pero a continuación se contradi-

54 AGEO, Real Intendencia, Subdelegación Nexapa-Quiechapa, 1814-1815, 81, 42. 
jo al decir que él mismo había favorecido y protegido a Pacheco cuando Gallardo lo persiguió por motivos y resentimientos particulares: «lo valenté y sostuve informando contra aquél [Gallardo] al que gobernaba la plaza de Oaxaca [es decir al intendente insurgente] hasta que logré quitarlo de su pueblo [se refiere a Gallardo de nuevo] manteniéndolo [a Nicolás Pacheco] en mi casa a este ingrato mixe y compañeros, dándoles bastimento para el camino y supliéndoles después dinero que aun me deben». Enfatizó, con cierta desesperación, que si el intendente decidía continuar el juicio presentaría testigos, además de los mencionados Calixto José y Jacobo Santiago, a «otros muchos», incluyendo el gobernador de Mazatlán. ${ }^{55}$ Con esta declaración Ponze de León ponía en evidencia que su relación con el pueblo de Mazatlán era estrecha e implicaba intereses más allá del formalismo entre autoridad real y pueblo tributario.

Una vez que Melchor Álvarez recibió la contestación del subdelegado de Nexapa, envió el caso al licenciado Manuel María Mimiaga, auditor de guerra. ${ }^{56}$ Éste mandó su respuesta a finales de enero de 1815. En ella valoró las acciones tanto del comandante Calixto Pérez como de los «soldados de Mazatlán», es decir, de Nicolás Pacheco y su grupo. De igual forma, destacó la importancia del respeto a la jurisdicción del juez de Nexapa y señaló la omisión del comandante de Puxmetacán al no enviar a los indios de Mazatlán que requería el subdelegado de Nexapa. Advirtió al intendente Álvarez que:

Es muy conveniente y acertado proteger el entusiasmo de los que han dado pruebas de fidelidad al legítimo gobierno y se han sacrificado con sus buenos servicios en defensa de la Patria; pero también es preciso e indispensable sostener la noble autoridad de los jueces territoriales que están puestos por el mismo gobierno para la recta administración de justicia y que se les guarden los debidos respetos, porque de lo contrario, desconociéndose las autoridades constituidas, menospreciándose su jurisdicción y excediéndose cada uno de la que por su debido empleo le corresponde, se agrian los ánimos, se fomentan las discordias, se da lugar a la arbitrariedad y se entorpece el régimen y buen orden que se ha establecido de que depende la seguridad y permanencia del Estado. ${ }^{57}$

El texto anterior refleja la preocupación de los realistas de Oaxaca, ya que, a pesar de haberse retirado los insurgentes de la capital de la intenden-

55 Idem.

56 Mimiaga había sido teniente de letrado y asesor ordinario del intendente insurgente Murguía y Galardi. Hernández Dávalos, 2008, 2.

57 AGEO, Real Intendencia, Subdelegación Nexapa-Quiechapa, 1814-1815, 81, 42. 
cia en marzo de 1814, éstos mantenían una fuerte presencia en la zona de la mixteca, la costa y Tuxtepec. La mixteca fue escenario de numerosas batallas desde 1812 hasta $1817 . .^{58}$ Geográficamente era un punto vital para el gobierno realista, ya que por ahí pasaba el camino real a Puebla, la ciudad de México y Veracruz. Era también la principal fuente de abastecimiento de la intendencia de Oaxaca.

La región de Nexapa se ubicaba entre el valle de Oaxaca y Tehuantepec, por donde discurría el camino real a Guatemala. Esta era la retaguardia del frente realista. Representaba su segunda vía de comunicación, suministro y escape ante un eventual avance insurgente sobre la capital. ${ }^{59}$ Ante esta situación, los realistas oaxaqueños no podían permitir quedarse aislados y por consiguiente evitaron tener conflictos internos. Trataron de calmar las rivalidades locales generadas por suspicacias y rumores que involucraban a funcionarios civiles, religiosos, comandantes de las milicias y rebeldes indultados.

Finalmente, Mimiaga recomendó que si Calixto José y Jacobo Santiago tenían alguna queja contra el comandante de Puxmetacán o Nicolás Pacheco que la presentaran «por ahora» en la comandancia general. Melchor Álvarez envió una copia de la respuesta del auditor de guerra tanto a Ponze de León como a Calixto Pérez para que «les sirva de gobierno de lo determinado en este expediente y tenga un efecto cumplido». ${ }^{60}$

Después de conocer estas dos versiones de los hechos de Mazatlán, quedan más preguntas que respuestas. Las principales incógnitas son las acciones de Nicolás Pacheco y las del propio subdelegado Ponze de León. Pero antes de entrar en especulaciones, adelanto una primera conclusión: la llegada de los insurgentes a Oaxaca no pasó desapercibida para los mixes de la zona baja. La presencia insurgente provocó la movilización de indígenas de varios pueblos que nutrieron tanto a fuerzas realistas como a los rebeldes. No obstante, en el caso concreto de Mazatlán, lo que impulsó la integración a la lucha armada fueron pugnas locales por el control político. La partida que lideraba Rafael Gallardo, aprovechando la invasión y el control insurgente de la intendencia, trató de desplazar del poder político al gobernador y los alcaldes de su pueblo. Gallardo obligó a someterse a su liderazgo a Nicolás Pacheco y a otros que habían sido o eran parte de la

58 López Bárcenas, 2012.

59 En 1812, el obispo de Oaxaca, Bergoza y Jordán, salió huyendo de los insurgentes por el camino real a Tehuantepec-Guatemala. Gay, 1978, 405.

60 AGEO, Real Intendencia, Subdelegación Nexapa-Quiechapa, 1814-1815, 81, 42. 
milicia realista de Puxmetacán con los que, al mismo tiempo, tenía una rivalidad política. Al sobrevenir la recuperación de la ciudad de Oaxaca por los realistas, Gallardo abandonó el pueblo de Mazatlán para unirse a las fuerzas insurgentes. Viéndose en una situación crítica, Calixto José y su grupo decidieron indultarse en Oaxaca, mientras que Nicolás Pacheco y sus compañeros permanecieron en el pueblo. Cuando el grupo realista de Puxmetacán arribó a Mazatlán, Pacheco y sus compañeros se incorporaron a ella. Finalmente, por temor a las represalias de Nicolás Pacheco, Calixto José acudió ante el juez de Nexapa.

Una interrogante importante es el papel que jugaron el gobernador y los demás miembros del cabildo indígena de Mazatlán frente a las pugnas entre Gallardo, Pacheco y Calixto José. Pareciera que las autoridades de Mazatlán evitaron involucrarse directamente en el conflicto entre facciones de su pueblo y entre realistas e insurgentes. Así, por ejemplo, su actitud fue ambigua al no acatar la orden del comandante realista de Puxmetacán de apresar a sus parientes insurgentes y entregárselos, pero tampoco desobedecieron completamente la instrucción, pues de algún modo convencieron u obligaron a sus familiares a presentarse en el juzgado de Nexapa, jurisdicción que les correspondía. Van Young, en su análisis sobre el comportamiento de las autoridades de los pueblos indígenas durante el movimiento insurgente, afirma que la participación activa de los notables indígenas en la insurrección fue porcentualmente baja (un diez por ciento aproximadamente), debido a «su vinculación con el régimen colonial y con los españoles poderosos que lo encarnan localmente $»{ }^{61}$ Pero resulta que las mismas autoridades tampoco respondieron ante la orden de su juez español cuando éste les pidió que le presentaran a Nicolás Pacheco. Es posible que no lograran convencer a Pacheco y los suyos o que éstos hábilmente recurrieran al intendente, que era la autoridad máxima en la región, para evitar al subdelegado y esquivar su castigo.

Lo anterior refleja una crisis interna de las autoridades del pueblo y un vacío de poder aprovechado principalmente por Pacheco. La acusación de este último contra el subdelegado de Nexapa de estar a favor de los insurgentes puede interpretarse como una estrategia para desviar la atención sobre su persona y sus actos. ${ }^{62}$ ¿Pertenecía Nicolás Pacheco a alguna

61 Van Young, 2006, 309.

62 Borah, 1996, 205, refiere la existencia de casos similares ocurridos desde el siglo XVII, que se enmarcaban en cambios de la estructura de poder, luchas de facciones al interior de los pueblos o el asentamiento de gentes nuevas. 
familia de notables en su pueblo? ¿Tenía alguna aspiración política dentro de su comunidad que rivalizaba con Gallardo y con las autoridades en turno? Son preguntas sin respuesta por falta de información. No obstante, refiero algunos detalles que indican la importancia a nivel local de su persona. El hecho de haber recibido ayuda directa del subdelegado hace suponer que por lo menos tenía una posición privilegiada en su comunidad además de ser un tipo hábil, conocedor de la jerarquía de la administración provincial española. También refleja ser un individuo con capacidad para costear un escribano y el envío a Oaxaca de la carta referida al principio de este apartado. Si su objetivo era deshacerse de Gallardo, desprestigiar al gobernador y alcaldes de su pueblo, así como evitar enfrentar al subdelegado con quien pudo tener algún trato o deuda económica, los hechos demuestran que tuvo éxito en un corto plazo: Gallardo se fue con las tropas insurgentes que abandonaron la ciudad de Oaxaca el 29 de marzo de 1814, Ponze de León dejó de ser subdelegado en junio de $1815,{ }^{63}$ finalmente, él y su grupo quedaron como los únicos miembros de su pueblo fieles a la causa realista reconocidos por el comandante-intendente de Oaxaca.

Sobre el subdelegado de Nexapa queda la duda de si realmente era simpatizante de los insurgentes o fue obligado a permanecer en su puesto durante la ocupación insurgente como otros criollos que habían sido funcionarios del gobierno real. ${ }^{64} \mathrm{Me}$ inclino por la primera opción puesto que, además de sus declaraciones contradictorias respecto a su relación con los mixes insurgentes de Mazatlán, en las elecciones para delegados al congreso de Chilpancingo, Ponze de León figura como representante de Nexapa. ${ }^{65}$ Quizás, de no haber sido por la denuncia de Nicolás Pacheco que puso en entredicho su fidelidad hacia los realistas, su caso hubiera pasado desapercibido y habría seguido ocupando el cargo de subdelegado.

\section{Nexapa y Villa Alta: San Pedro Acatlán, pueblo «insurgentado», contra Jaltepec de Candayoc, pueblo «realista»}

Mientras Rafael Gallardo se establecía en San Juan Mazatlán en 1812 y efectuaba incursiones por diversas partes de la zona mixe, llegando has$6,11,11$

63 José Vicente González, subdelegado interino en 1815, AHJO, Yautepec, Civil, 1813-1818,

64 Tanto Manuel María Mimiaga como José María Murguía y Galardí siguieron ocupando cargos en el gobierno realista después de la ocupación insurgente, ver Hamnett, 1971, 163.

65 Hernández Dávalos, 2008, 3. 
ta Villa Alta, cabeza del mismo distrito, los pueblos de Acatlán, de la subdelegación de Nexapa, y el de Candayoc, de Villa Alta, se enfrentaban entre sí acusándose unos a otros de realistas y de insurgentes.

El pueblo de Acatlán se quejaba en una carta a su subdelegado, José Román Ponze de León, con fecha del 12 de enero de 1814 de haber sido agredido por el pueblo de Candayoc. Expusieron que habían ido a limpiar sus algodonares ubicados en las tierras que disputan con Candayoc. Al segundo día de estar trabajando, llegaron sus rivales a un sitio donde había un «estacamento». Es decir, una marca que dividía la tierra. Los de Candayoc preguntaron a los de Acatlán que quién había dado orden de poner el «estacamento»; éstos respondieron que «dos principales». ${ }^{66}$ Acto seguido, los primeros agarraron a uno de los principales acatecos de nombre Santiago de la Cruz y lo amarraron a un árbol. Después se fueron a la milpa de «humedad» donde estaban rozando otros tres indígenas de Acatlán, a quienes les pegaron mientras les preguntaban también sobre quién había ordenado poner el estacamento. Éstos respondieron que «Don Benito Rocha», gobernador insurgente de Oaxaca, a lo que respondieron los de Candayoc que «aquí está los gachupines», que ellos eran compañeros de los gachupines y que «ustedes [los de Acatlán] están con los insurgentes, alcahuetes de los insurgentes son ustedes».

Los enfrentamientos siguieron en los días siguientes hasta que, al cuarto día, los de Acatlán lograron apresar a tres miembros de Candayoc e hicieron un ritual en donde uno de los principales acatecos les leyó un «papel». Según estos últimos, los de Candayoc no querían saber el contenido de dicho papel y habían golpeado a uno de sus principales:

[...] salieron dos principales pidiendo perdón, hincados con un papel los principales, dieron un palo a la cabeza que le rompieron la cabeza a un principal llamado Raymundo Agustín, entonces se levantaron los principales [y] se estuvieron peleándose donde prendieron a tres de Candayoc y entonces les leyeron el papel que no querían [que] los leyeran delante de ellos, entonces nos pasamos al otro lado del estacamento de los de Tutla [pueblo vecino], pasamos a los tres que prendieron cuando fue el pleito al lado del río, le leímos el papel y después volvimos a pasar para que se fueran con sus compañeros y cogimos unos machetes y sombreros. ${ }^{67}$

Quedaron diez heridos de Acatlán como saldo del enfrentamiento, no sabemos si Candayoc tuvo heridos ni tampoco el contenido del papel que

66 Por lo general, los principales eran nobles y ancianos con experiencia en el manejo de los gobiernos indígenas. Arrioja, 2008a, 189.

67 AHJO, Yautepec, Civil, 1813-1818, 6, 11, 25-30. 
mostraron los primeros a los segundos. Pero lo que hicieron los principales de Acatlán con los tres indígenas de Candayoc, es decir, pasearlos por los linderos de los pueblos, leyendo el papel en cada una de las colindancias, tiene cierto parecido con lo que hacían los subdelegados en los litigios de tierras cuando efectuaban una dotación de tierras o realizaban una «vista de ojos». ${ }^{6}$

Este no era el primer encuentro violento entre ambos grupos, aunque sí fue el que más heridos reportó. En 1812, justo cuando los insurgentes se establecieron en la ciudad de Oaxaca, hubo otra refriega entre ambos pueblos. A primera vista, y teniendo presente el caso de Mazatlán como foco insurgente y el de Puxmetacán como base de una milicia realista, se podría interpretar que Acatlán siguió el camino de Mazatlán, pueblo vecino que pertenecía a la misma parroquia. Cabe destacar que Acatlán era la cabecera de la parroquia a la que estaban sujetos los pueblos de Mazatlán, Malacatepec y Tutla. Se recordará que los gobernadores de estos pueblos, a excepción del de Malacatepec, fueron llamados en 1814 por el intendente realista Melchor Álvarez para cuestionarlos por ser simpatizantes de los insurgentes. Tanto Mazatlán como Tutla fueron absueltos, no así Acatlán. El pleito de tierras pendiente de resolución debió de haber influido para que Acatlán no fuera absuelto como los demás. Por su parte, Candayoc era pueblo sujeto a la parroquia de Puxmetacán, ambos reconocidos por Melchor Álvarez como fieles a los realistas (ver mapa III). ${ }^{69}$

Sin embargo, el motivo real de la lucha entre Acatlán y Candayoc poco tenía que ver con el conflicto armado entre insurgentes y realistas. La principal causa del enfrentamiento de los dos pueblos era la propiedad de las tierras en donde se habían desatado los enfrentamientos antes mencionados, las cuales formaban parte del tablón de Jaltepec. ${ }^{70}$ Como ya se ha

68 En estas ceremonias estaban presentes las autoridades de los pueblos involucrados y, junto con los funcionarios reales, recorrían los linderos y aprobaban la ubicación de las mojoneras que marcaban las divisiones entre los territorios. En consecuencia, el papel referido pudo haber contenido la descripción de los linderos por parte de alguna autoridad española. Para más detalles de las ceremonias de dotación de tierras, vista de ojos y posesión de predios, ver Chevalier, 1985, 86, y Solano, 1984, 27. En la primera parte del pleito —-que va de 1790 a 1807--, en 1801, Rafael Cuartero, un español comisionado para resolver el conflicto enviado por el intendente de Oaxaca, realizó una de las ceremonias antes mencionadas, en la que participaron las autoridades de Acatlán y Candayoc. AHJO, Yautepec, Civil, 1796-1802, 2, 5, 178-180v.

69 Arrioja, 2008a, 595.

70 La palabra «tablón» se usa para determinar las tierras que están a las orillas de los ríos. En este caso se le denomina «tablón de Jaltepec» porque el río que las atraviesa recibe el nombre de Jaltepec. Para mayores detalles del tablón, ver Escalona, 2012. 


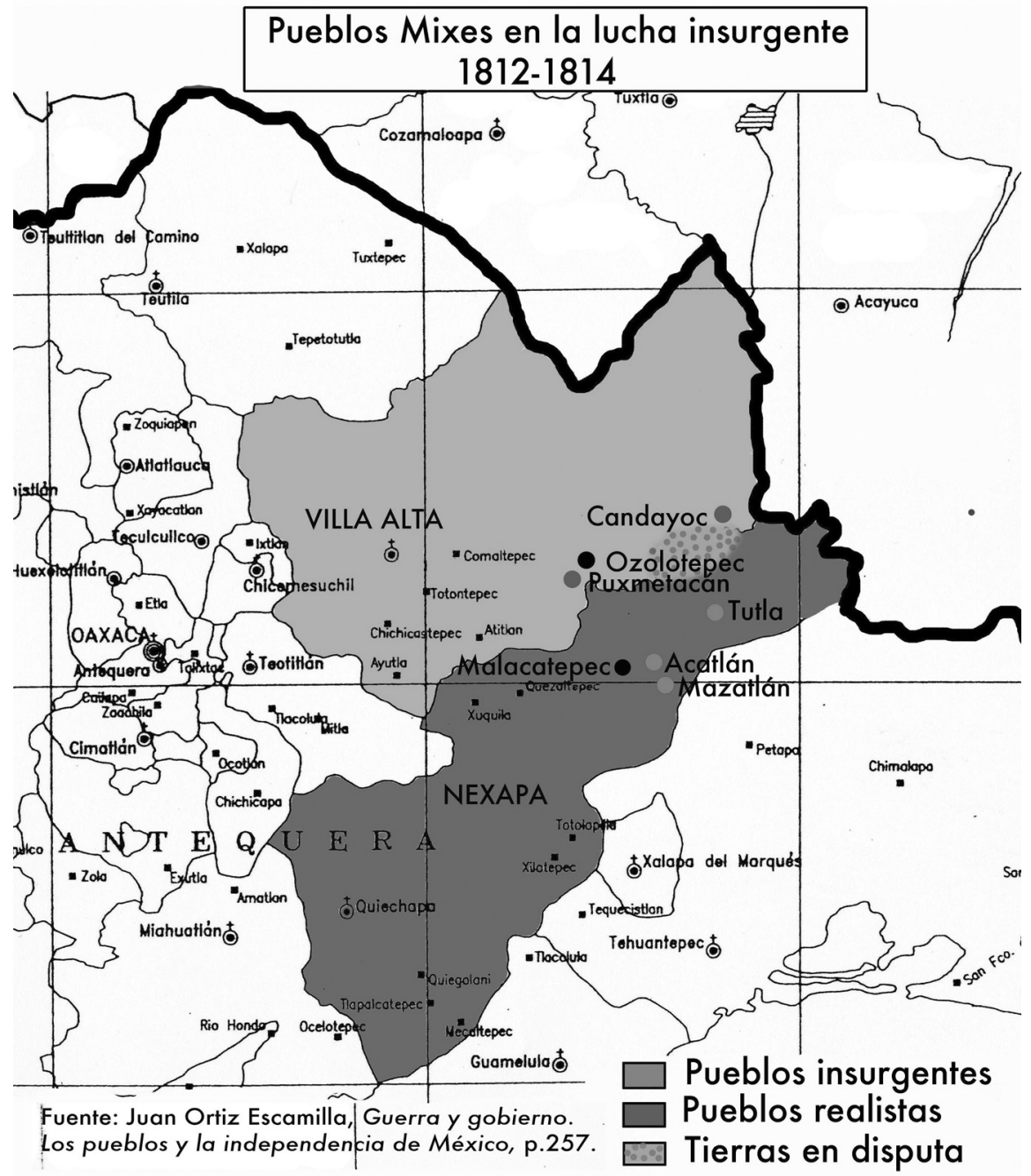


dicho en otro trabajo en donde se analiza el pleito desde su origen, lo ocurrido durante la ocupación insurgente fue un episodio más en el conflicto agrario entre ambas comunidades que había comenzado en $1790 .{ }^{71}$ En ese entonces, también estaban involucrados en el litigio los pueblos de Santiago Tutla, aliado de Acatlán, y Puxmetacán, aliado de Candayoc. ${ }^{72}$

Los cuatro pueblos tenían colindancias entre sí pero pertenecían a dos jurisdicciones distintas: Puxmetacán y Candayoc correspondían a la de Villa Alta, mientras que Acatlán y Tutla, a la de Nexapa. Todos ellos se dedicaban al cultivo del maíz, el fríjol y el algodón, así como al corte de maderas finas como el cedro. Las tierras disputadas se localizaban en la vega de un río caudaloso, el río Jaltepec, por lo que se podían aprovechar todo el año cultivando, simultáneamente, algodón y maíz..$^{73}$ Las relaciones geográficas de 1777 dan cuenta de la existencia en los cuatro pueblos de una semilla de maíz amarillo que daba tres cosechas al año. ${ }^{74}$ El algodón era uno de los productos más valorados de la región. ${ }^{75}$ Gracias a la siembra del mismo, los pueblos podían afrontar las cargas tributarias y demás pagos que hacían a la Corona española que, con las reformas borbónicas, se habían incrementado. Del mismo modo, también servía como motor del repartimiento de mercancías, el cual, a pesar de la oposición del intendente, seguían practicando los subdelegados de ambas jurisdicciones. Los cuatro pueblos hilaban el algodón para luego convertirlo en mantas, usaban una parte de ellas para confeccionar la ropa con la que se vestían y el resto, que era la mayoría, la entregaban a los agentes que los subdelegados tenían en las cabeceras parroquiales de su jurisdicción. ${ }^{76}$ Durante el último tercio del siglo XVIII varias epidemias ${ }^{77}$ sequías y heladas, afectaron a los pueblos indígenas de Oaxaca. ${ }^{78}$ En este contexto de hambre y enfermedad, la zona mixe baja no fue la excepción. Los pueblos de Candayoc y Acatlán,

71 Idem.

72 Los datos anteriores dan un panorama en el cual la mayoría de los pueblos de la parroquia de Acatlán, de la jurisdicción de Nexapa, simpatizaban con los insurgentes, mientras que el pueblo cabecera de la parroquia de Puxmetacán y su sujeto Candayoc, de la subdelegación de Villa Alta, se asumían realistas. Ver mapa III.

73 Murguía y Galardi, 1827.

74 Esparza, 1994, 23-37.

75 Villa-Señor y Sánchez, 1952, 157.

76 Estos agentes estaban encargados de distribuir las mercancías y de recoger el pago de las mismas en dinero o en productos locales. Para más información sobre los repartimientos en Oaxaca al final de la época colonial, ver Arrioja, 2008b.

77 En 1789 hubo una epidemia de tifus y en 1797 una de viruela. Arrioja, 2008a, 587.

78 Varias heladas y sequías se sucedieron entre 1785 y 1789 . Idem. 
por ejemplo, sufrieron una considerable disminución de su población entre 1742 y $1789 .{ }^{79}$ Este fue el escenario en que comenzó el pleito en 1790.

En 1802, los pueblos de Puxmetacán y Tutla establecieron un acuerdo que consistió en que el primero reconoció el derecho de posesión sobre la porción de tierra denominada «La Isleta». A partir de entonces, Acatlán y Candayoc siguieron el pleito sin sus respectivos aliados. En 1807, los dos pueblos (Acatlán y Candayoc) llegaron a un arreglo y por espacio de cinco años no hubo mayores problemas entre ellos. Sin embargo, esta tranquilidad se rompió en 1812 cuando los de Acatlán presentaron una solicitud sobre los derechos de propiedad de la tierra en disputa.$^{80}$ Esto encendió los ánimos de Candayoc y volvieron los enfrentamientos entre ambos pueblos, principalmente cada vez que se encontraban en las tierras disputadas. No se sabe si la solicitud de los de Acatlán se hizo antes o después de la llegada de Morelos a Oaxaca. En cualquier caso, la cronología de la documentación demuestra que el cambio de gobierno en la ciudad de Oaxaca no fue un obstáculo para que los pueblos siguieran el pleito en los juzgados locales.

Al ver que los de Acatlán seguían haciendo gestiones sobre la propiedad ante las autoridades insurgentes y que los jueces de Nexapa no les habían favorecido en los dictámenes anteriores, los de Candayoc trataron de que la continuación del juicio se realizara en el juzgado de Villa Alta. En octubre de 1813, Juan Pérez, indígena principal de Candayoc, se presentó en Quiechapa para recoger el expediente del litigio con Acatlán que previamente habían solicitado..$^{81}$ A continuación, por conducto de su abogado pidieron al intendente insurgente el cambio de jurisdicción, éste consultó con el asesor provisional Manuel de Leal y Araujo, de quien se desconoce el contenido de su recomendación, pues en ese momento abandonaron los insurgentes la ciudad y quedó pendiente la respuesta..$^{82}$

Como se refirió al principio del apartado, unos meses antes de la vuelta de los realistas a la ciudad de Oaxaca, los dos pueblos se habían enfren-

79 Candayoc tenía 414 habitantes en 1742, 295 en 1781, 239 en 1789 y 323 en 1826. Ibidem, p. 591. Mientras que Acatlán en 1742 tenía alrededor de 400 habitantes, en 1783 se redujeron a 271 y en 1826 eran 273. Los datos de 1742 provienen de Villa-Señor y Sánchez, 1952, 157; para los de 1783, ver AGN, Alcaldes Mayores, 1783, 7, 29, 36-38; finalmente, para el año de 1826, ver Murguía y Galardi, 1827. Más detalles del pleito en Escalona, 2012.

80 No sabemos qué tipo de trámite iniciaron los de Acatlán en 1812. Es probable que fuera la solicitud de confirmación de la propiedad del predio, suponiendo que hubiesen tenido la posesión en 1807. Sobre la confirmación de la propiedad, ver Solano, 1984, 28-30.

81 AHJO, Yautepec, Civil, 1813-1818, 6, 11, 1-1v.

82 Ibidem, 27 y $27 \mathrm{v}$. 
tado al encontrarse miembros de ambas partes en las tierras en disputa. Llama la atención que los de Candayoc recalcaran su fidelidad a los realistas y acusaran a los de Acatlán de insurgentes. ¿Sabían los de Candayoc que los realistas pronto ocuparían la ciudad de Oaxaca? Es probable que así fuera, como hemos referido anteriormente. A pesar de las largas distancias y los malos caminos de la provincia, la información circulaba y los rumores abundaban. También es importante destacar que el hecho de tener una milicia realista en el pueblo vecino de Puxmetacán pudo ser una ventaja en cuanto a que supieron de la noticia antes que los de Acatlán. Ello explicaría el ataque de Candayoc en vísperas de la retirada insurgente de la capital provincial en marzo de 1814.

El litigio continuó una vez más con las autoridades realistas que debatían sobre la solicitud del cambio de jurisdicción hecha por Candayoc. La situación en la capital oaxaqueña era complicada por las rivalidades entre los funcionarios realistas que volvieron, los que habían sido parte del gobierno insurgente de manera «forzada» y los que habían tenido una actitud ambigua y fueron perdonados. La inestabilidad política en la intendencia influyó en el alargamiento del conflicto entre los dos pueblos. Así, por ejemplo, el asesor de guerra Mariano Castillejos, consultado en 1815 por el subdelegado provisional José Vicente González sobre la solución del conflicto entre los dos pueblos, había dado su veredicto a favor de los de Acatlán. ${ }^{83}$ En respuesta, el abogado de Candayoc, Mateo Forte, después de polemizar la recomendación de Castillejos, pidió que no se le consultase más «por odioso y sospechoso». ${ }^{84}$

Se observa que, dentro del litigio de tierras entre los dos pueblos, salieron a la luz también los pleitos entre criollos y/o peninsulares que habían tenido diferencias por sus actitudes frente al movimiento insurgente. En este caso, tanto Manuel Castillejos como Mateo Forte eran letrados y habían participado en el gobierno insurgente, pero la diferencia era que el primero había sido acusado en 1809 de «proclamas sediciosas» junto con su hermano Julián Castillejos ${ }^{85}$ Los hermanos Castillejos se habían mostrado a favor de la idea de la creación de una nación independiente de España ${ }^{86}$ debido a ello, varios criollos realistas como Mateo Forte los señalaron repetidamente como traidores o «poco fiables».

83 Ibidem. 43-44.

84 Ibidem, 46-46v.

85 AGN, Infidencias, 6, 11.

86 Hamnett, 1971, 162. 
Durante el resto del año de 1815 y hasta 1817 , fueron y vinieron en una y otra dirección por los caminos entre Acatlán, Candayoc, Villa Alta, Quiechapa y Oaxaca un gran número de cartas, dictámenes de asesores, citatorios, escritos de los apoderados y todos los papeles acumulados desde 1790, para determinar finalmente que el juicio debía de seguirse en el juzgado de Nexapa. A principios de 1818, en febrero de ese año, el letrado y asesor del pueblo de Candayoc, Mateo Forte, presentó al subdelegado de Nexapa la copia de los documentos en los que se asentó la operación por la cual este pueblo, junto con Puxmetacán y Ozolotepec, había obtenido la propiedad del tablón de Jaltepec en 1737. Los de Candayoc habían solicitado desde 1812 la copia de los «títulos de propiedad» al escribano José Álvarez, quien los tuvo listos a finales de $1813 .{ }^{87}$ No se sabe la razón por la cual se entregaron hasta febrero de 1818 y no antes.

Es notable la similitud entre este caso y el de Mazatlán, donde las pugnas políticas entre facciones rivales, que muy probablemente ya existían antes de la llegada de los insurgentes a Oaxaca, determinaron la participación de un sector de la población en la rebelión. El conflicto entre Candayoc y Acatlán se había iniciado antes de 1812 y la guerra de independencia fue un factor circunstancial que se sumó a la complejidad del mismo. Los dos pueblos trataron de aprovechar la coyuntura en su favor, asumiendo alguno de los bandos. Así mismo, ante la circulación de noticias sobre los resultados de enfrentamientos armados entre realistas e insurgentes en otras partes del territorio oaxaqueño, cada uno de los pueblos llevaron acciones locales que buscaban sacar provecho de esa información para consolidar su posición frente al rival y a las autoridades insurgentes o realistas.

Candayoc fue el pueblo que obtuvo mayores ventajas gracias a sus acciones directas - enfrentamientos directos con su adversario en las tierras disputadas - e indirectas - con litigios en los juzgados. Aunque el resultado de dichos actos no se reflejó de manera positiva en lo inmediato, a largo plazo sí que tuvieron un efecto que benefició sus intereses. En 1812, cuando todo parecía indicar que perderían el tablón de Jaltepec porque los dictámenes emitidos hasta ese momento favorecían la postura de Acatlán, sobrevino la intervención insurgente en la intendencia. El nuevo escenario de entonces parecía seguir en su contra al ocasionar la demora en la obtención de sus títulos de propiedad debido a la inestabilidad política y al cambio de gobierno. La situación pareció empeorar con la aparición del grupo

87 AHJO, Yautepec, 1813-1818, Civil, 6, 11, 128v-129. 
insurgente de Rafael Gallardo en Mazatlán, que contaba con el apoyo de los pueblos vecinos, entre los que se encontraba su rival. Por si fuera poco, el propio subdelegado de Nexapa, jurisdicción a la que pertenecía el pueblo adversario, había sido reconocido por el gobierno insurgente y significaba un elemento más en su contra, ya que el litigio era llevado por el juzgado de dicho funcionario.

Sin embargo, todo cambió en 1814 con la vuelta de los realistas y la balanza se inclinó a favor de Candayoc. El subdelegado de Nexapa fue sustituido por uno interino, Acatlán y los demás pueblos «insurgentados» fueron vistos con desconfianza por el nuevo intendente, mientras ellos, gracias a su discurso de fidelidad, quedaron fortalecidos ante el nuevo gobierno español de la provincia. También les ayudó el haber contado con una milicia realista en el pueblo vecino de Puxmetacán, en la que seguramente habría más de un mixe de Candayoc que les sirvió de fuente de información. Finalmente, con la intervención de su abogado Mateo Forte, en 1818 conseguían una copia de los títulos de propiedad que incluía el tablón de Jaltepec emitidos en 1737 como resultado de una composición de tierras. Estos documentos habían sido recogidos en 1784 por Sancho Pisón, alcalde mayor de Villa Alta, quien también fungía como Subdelegado de Tierras y Aguas y como tal había enviado los documentos al juzgado de Tierras y Aguas en la ciudad de México. Desde finales del siglo XVIII el pueblo de Candayoc había estado esperando la vuelta de sus títulos. Tardaron más de 30 años en recuperarlos.$^{88}$ Como ya señaló Romero Frizzi, «los pueblos soportaron esos gastos impresionantes de recursos y energía humana producidos por el sistema judicial novohispano y sus procedimientos sólo para debilitar a su enemigo, al pueblo rival» ${ }^{89}$

\section{Comentarios finales}

En párrafos anteriores adelanté que la presencia insurgente en el territorio oaxaqueño sí tuvo un impacto en los pueblos mixes de la zona baja y que participaron activamente en el conflicto al incorporarse tanto a las fuer-

88 En 1789, Candayoc, Puxmetacán y otros pueblos mixes de la jurisdicción de Villa Alta que colindaban con la subdelegación de Nexapa habían solicitado sus «títulos y documentos». Los pueblos mixes señalaron tener problemas con los pueblos colindantes de la jurisdicción de Nexapa por carecer de sus títulos con los que aclarar las «dudas que se suscitan». AHJO, Villa Alta, Civil, 1789, 25, 6.15, 44 y $44 \mathrm{v}$.

89 Romero Frizzi. 2004, 26. 
zas realistas como a las insurgentes. Igualmente señalé que lo hicieron con sus propias motivaciones y no impulsados por las ideas independentistas que tenían líderes insurgentes como Hidalgo y Morelos. Las razones de su involucramiento obedecían a comportamientos propios de su cultura política local, es decir, a la búsqueda de soluciones a problemas cotidianos en el interior y en el exterior de las comunidades.

El caso de Mazatlán representa una pugna entre facciones que se disputan el control del gobierno local. Por su parte, Candayoc y Acatlán muestran la lucha por la tierra, por el control territorial y la persistencia o búsqueda de una autonomía. Lo anterior bien puede vincularse a la propuesta de Van Young sobre el anarquismo localocéntrico que permeaba en varias comunidades rurales de la Nueva España a finales del período colonial. Este autor destaca la poca visión política de los indígenas más allá del ámbito de sus pueblos y, en consecuencia, propone que el impulso de muchos de ellos para unirse a las tropas insurrectas fueron rencillas o conflictos locales, sin que en ellos influyera una conciencia política a favor de la independencia de España..$^{90}$ En este punto cabe aclarar que, en regiones como Michoacán, la incorporación a la lucha insurgente por los indígenas presentó otras características que contradicen la propuesta de Van Young. Los indígenas del obispado de Michoacán habían sufrido en el último tercio del siglo XVIII las consecuencias de las primeras reformas borbónicas, que agravaron la supervivencia de sus comunidades. A principios del siglo XIX tenían ya una conciencia de los efectos negativos de la implementación de las nuevas políticas para sus comunidades, situación que los llevó a participar de manera más directa y masiva en el movimiento insurgente de 1810. ${ }^{91}$ Así pues, caben muchos matices en la aseveración hecha por Van Young, especialmente en lo que se refiere a la valoración de las motivaciones indígenas para incorporarse a la lucha armada.

Los dos ejemplos tratados aquí representan, a mi modo de ver, dos logros de sectores de la población indígena que supieron aprovechar la coyuntura política en su favor. Nicolás Pacheco pudo librarse de su rival político dentro del pueblo —-que era Rafael Gallardo- - y legitimarse ante

90 Van Young, 2006, 722 y 846.

91 Martínez Baracs, 2010. Taylor, 2008, 187-222, refiere un caso similar para la región de Guadalajara. Este autor hace mayor énfasis en una desestructuración más temprana de la propiedad colectiva de la tierra y, por ende, de la vida comunitaria relacionada con la formación de las haciendas en el centro de Jalisco. Lo anterior incidió en una mayor participación de la población indígena de aquella zona en la guerra de independencia. 
el gobierno español. Por su parte, Candayoc consiguió recuperar una porción de las tierras del tablón de Jaltepec. En ambos casos, la estrategia de manipulación de los discursos del pueblo de Candayoc y de Nicolás Pacheco esgrimidos frente a las autoridades realistas surtió efecto.

Por otro lado, es importante resaltar la variedad de las reacciones que tuvieron los pueblos de las dos subdelegaciones. Éstas muestran una dinámica histórica propia de las regiones como Oaxaca, influidas por una geografía predominantemente montañosa, en donde han confluido una diversidad de pueblos indígenas que, al mismo tiempo que comparten muchos rasgos culturales, responden de manera diferenciada a coyunturas exteriores. Cabe señalar que los pueblos indígenas mixes funcionaban (en la actualidad lo siguen haciendo) como entidades colectivas, con una identidad vinculada a un territorio y con una dinámica determinada por la combinación de fuerzas centrípetas y centrífugas. Las primeras se manifestaban en los conflictos internos entre facciones ocasionadas por el control político del gobierno local, y las segundas se dirigían al exterior a través de las disputas o rivalidades con los pueblos vecinos.

Finalmente, enfatizo que el aislamiento geográfico de los pueblos indígenas durante la época colonial, por lo menos en el caso de los mixes, no se tradujo en un aislamiento político. Los litigios constantes en los juzgados españoles y la complejidad de los mismos mantuvieron una movilización constante de documentos, recursos y personas desde territorios remotos hasta la capital de la provincia y del virreinato. Esto permitió también que las noticias de lo que ocurría en otras regiones de la provincia y de la Nueva España llegaran a los pueblos y reaccionaran ante ellas de acuerdo a sus intereses. Demostraron tener una cultura política propia que si bien no correspondía a la de otros sectores de la población novohispana, por ejemplo los criollos, ello no significa que tuviese menos importancia.

Autores como Taylor han señalado que los pueblos indígenas de Oaxaca durante el siglo XVIII participaron activamente en varias revueltas y eso los hizo «buenos rebeldes pero deficientes revolucionarios» en la época de la independencia. ${ }^{92}$ Sin embargo, ¿por qué presuponer que debían ser «buenos revolucionarios» según el modelo liberal? o ¿por qué habrían de comportarse de una manera que no correspondía a sus intereses? Irónicamente, gracias a su bajo perfil «revolucionario», muchos indígenas oaxaqueños todavía mantienen el control de su territorio al mismo tiempo

92 Taylor, 2008, 208. 
que han buscado formas de adaptarse y relacionarse con el llamado mundo «moderno». Con esto no pretendo caer en la idealización de las sociedades indígenas oaxaqueñas, pues como toda sociedad tiene sus propias contradicciones. Pero sí creo necesario señalar que, juzgarlos por no reaccionar de acuerdo a las ideologías imperantes en ciertos periodos históricos, es negar una parte importante de su historia.

Recibido el 8 de octubre de 2012 Aceptado el 25 de febrero de 2013

\section{Referencias generales}

\section{Archivos}

AGN: Archivo General de la Nación, Distrito Federal, México

AGEO: Archivo General del Estado de Oaxaca, Oaxaca

AHJO: Archivo Histórico del Poder Judicial de Oaxaca, Oaxaca

\section{Páginas web}

www.nacionmulticultural.unam.mx

www.cdi.gob.mx

\section{Bibliografía}

Aninno, Antonio: «Cádiz y la revolución territorial de los pueblos mexicanos, 1812-1821», en Annino, Antonio (coord.), Historia de las elecciones en Iberoamérica, siglo XIX, Buenos Aires, Fondo de Cultura Económica, 1995, 177-226.

Arrioja, Luis Alberto: Pueblos de indios, tierras y economía. Villa Alta (Oaxaca) en la transición de Colonia a República, 1742-1856, tesis doctoral, México, El Colegio de México, 2008a.

Arrioja, Luis Alberto: «De la prohibición a la persistencia: el repartimiento de mercancías en Villa Alta (Oaxaca), 1786-1834», en Traffano, Daniela (comp.), Reconociendo el pasado. Miradas históricas sobre Oaxaca, Oaxaca, Centro de Investigaciones y Estudios Superiores en Antropología Social (en adelante CIESAS)-Universidad Autónoma Benito Juárez de Oaxaca (en adelante UABJO), 2008b, 91-129. 
Borah, Woodrow: El Juzgado General de Indios en la Nueva España, México, Fondo de Cultura Económica, 1996.

Bustamante, Carlos María de: Cuadro histórico de la Revolución Mexicana iniciada el 15 de septiembre de 1810 por el C. Miguel Hidalgo y Costilla Cura del pueblo de Dolores en el Obispado de Michoacán, dedicado al Exmo. Sr. D. Ignacio Trigueros, secretario del Despacho y de Hacienda, I y II, México, edición de la Comisión Nacional para la celebración del sesquicentenario de la proclamación de la Independencia, 1961.

Cortés Máximo, Juan Carlos: «Separación de sujetos, guerra insurgente y ayuntamientos gaditanos: los pueblos indios en el oriente de Michoacán, 17501824» en Guzmán Pérez, Moisés (coord.), Guerra e imaginarios políticos en la época de las independencias, México, Universidad Michoacana de San Nicolás de Hidalgo, 2007, 89-136.

Cruz Pazos, Patricia: «Juan Moctezuma y Cortés: cacique, cura e insurgente (1754/1757-1816)», Revista Española de Antropología Americana, 41, 2, Madrid, 2011, 521-545.

Chance, John: La conquista de la sierra. Españoles e indígenas en la época de la colonia, México, CIESAS - Instituto Oaxaqueño de las Culturas, 1989.

Chevalier, François: La formación de los latifundios en México, México, Fondo de Cultura Económica, 1985.

Escalona Lüttig, Huemac: «Conflicto de tierras e insurgencia entre los mixes: San Juan Jaltepec de Candayoc contra San Pedro Acatlán, 1790-1819», en Arrioja, Luis Alberto y Sánchez Silva, Carlos (eds.), Conflictos por la tierra en Oaxaca. De las reformas borbónicas a la reforma agraria, Zapopan, El Colegio de Michoacán-UABJO, 2012, 73-111.

Escobar, Antonio: «Las dirigencias y sus seguidores, 1811-1816. La insurgencia en las Huastecas», en Terán, Marta y Serrano, José Antonio (eds.), Las guerras de independencia en la América Española, México, El Colegio de Michoacán-Instituto Nacional de Antropología e Historia-Universidad Michoacana de San Nicolás Hidalgo, 2002, 217-236.

Esparza, Manuel: Relaciones Geográficas de Oaxaca, 1777-1778, Oaxaca, CIESAS- Instituto Oaxaqueño de las Culturas, 1994.

Ferrer, Manuel: «Las comunidades indígenas de la Nueva España y el movimiento insurgente (1810-1817)», Anuario de Estudios Americanos, LVI-2, Sevilla, 1999, 513-538.

Gay, José Antonio: Historia de Oaxaca, II, Oaxaca, Gobierno del Estado de Oaxaca, 1978.

Guardino, Peter: El tiempo de la libertad. Cultura política popular en Oaxaca, 1750-1850, Oaxaca, UABJO-El Colegio de Michoacán-El Colegio de San Luis- Universidad Autónoma Metropolitana, 2009.

Hamnett, Brian: Politics and trade in southern Mexico, 1750-1821, Oxford, Cambridge University Press, 1971. 
Hamnett, Brian: Revolución y contrarrevolución en México y el Perú. Liberalismo, realeza y separatismo (1800-1824), México, Fondo de Cultura Económica, 1978.

Hamnett, Brian: Raíces de la insurgencia en México. Historia regional, 17501824, México, Fondo de Cultura Económica, 2010.

Hensel, Silke: «Bringing the state back in: La presencia del Estado a nivel localOaxaca en la época de la independencia», Potestas. Revista del Grupo Europeo de Investigación Histórica, 2, Castellón, 2009, 211-228.

Hernández Chávez, Alicia: La tradición republicana del buen gobierno, México, El Colegio de México- Fondo de Cultura Económica, 1993.

Hernández Dávalos, Juan: Colección de documentos para la historia de la guerra de independencia de 1808 a 1821, IV, México, Fondo de Cultura Económica, 2008.

Ibarra, Antonio: «De los delitos políticos y la vida privada: los infidentes novohispanos, 1809-1815 (escenas cotidianas de obediencia y disidencia)», Anu. estud. am., LII-2, Sevilla, 1995, 99-120.

Lenkersdorf, Gudrun: Repúblicas de indios. Pueblos mayas en Chiapas, siglo XVI, México, Plaza y Valdés Editores, 2010.

López Bárcenas, Francisco: «Los pueblos mixtecos en la Guerra de Independencia», en Sánchez Silva, Carlos (coord.): La guerra de independencia en Oaxaca. Nuevas perspectivas, Oaxaca, UABJO- Universidad Nacional Autónoma de México-CIESAS-El Colegio de MichoacánEl Colegio de Chihuahua-El Colegio de San Luis-El Colegio de JaliscoBiblioteca Miguel Lerdo de Tejada-Universidad Autónoma Metropolitana, 2012, 103-124.

Martínez Baracs, Rodrigo: «Los indios de México y la modernización borbónica», en García Ayluardo, Clara (coord.), Las reformas borbónicas, 1750-1808, México, Fondo de Cultura Económica, 2010, 23-82.

Mendoza, Edgar: Poder político y poder económico de los pueblos chocholtecos de Oaxaca: municipios, cofradías y tierras, 1825-1890, tesis doctoral, México, El Colegio de México, 2004.

Menegus, Margarita: «Los efectos de la insurgencia sobre la propiedad en la Mixteca», en Sánchez Silva, Carlos (coord.), La guerra de independencia en Oaxaca. Nuevas perspectivas, Oaxaca, UABJO-Universidad Nacional Autónoma de México-CIESAS-El Colegio de Michoacán-El Colegio de Chihuahua-El Colegio de San Luis-El Colegio de Jalisco-Biblioteca Miguel Lerdo de Tejada-Universidad Autónoma Metropolitana, 2012, 125-136.

Menegus, Margarita: La mixteca baja. Entre la Revolución y la Reforma. Cacicazgo, territorialidad y gobierno, siglos XVIII-XIX, México, Universidad Autónoma Metropolitana-UABJO-Congreso del Estado de Oaxaca, 2009. 
Murguía y Galardi, José María: Estadísticas del Estado libre de Oaxaca, Oaxaca, 1827.

Nahmad, Salomón: Fronteras étnicas. Análisis y diagnóstico de dos sistemas de desarrollo: proyecto nacional vs proyecto étnico. El caso de los ayuuk (mixes) de Oaxaca, México, CIESAS, 2003.

Ortiz Escamilla, Juan: Guerra y gobierno. Los pueblos y la independencia de México, Sevilla, Universidad Internacional de Andalucía-Universidad de Sevilla-Instituto Mora-El Colegio de México, 1997.

Ortiz Escamilla, Juan y Serrano, José Antonio (eds.): Ayuntamientos y liberalismo gaditano en México, México, El Colegio de Michoacán-Universidad Veracruzana, 2007.

Romero Frizzi, María de los Ángeles: «El poder de la ley. La construcción del poder colonial en una región indígena», manuscrito presentado en el Seminario de Historia, etnohistoria y disciplinas afines, Oaxaca, CIESAS, 2004.

Romero Frizzi, María de los Ángeles: «Conflictos agrarios, historia y peritajes paleográficos. Reflexionando desde Oaxaca», Revista de Estudios Agrarios, 47, México, 2011, 65-81.

Salinas, María del Carmen, Birrichaga, Diana y Escobar, Antonio (coords.): Poder y gobierno local en México 1808-1857, México, El Colegio MexiquenseEl Colegio de Michoacán, 2011.

Sánchez Silva, Carlos: «No todo empezó en Cádiz: simbiosis política en Oaxaca entre Colonia y República», Signos Históricos, 19, México, 2008, 8-35.

Sánchez Silva, Carlos (coord.): La guerra de independencia en Oaxaca. Nuevas perspectivas, Oaxaca, UABJO-Universidad Nacional Autónoma de MéxicoCIESAS-El Colegio de Michoacán-El Colegio de Chihuahua-El Colegio de San Luis-El Colegio de Jalisco-Biblioteca Miguel Lerdo de TejadaUniversidad Autónoma Metropolitana, 2012.

Solano, Francisco de: Cedulario de tierras. Compilación de legislación agraria colonial (1497-1820), México, Universidad Nacional Autónoma de México, 1984.

Taylor, William: «Bandolerismo e insurrección: agitación rural en el centro de Jalisco, 1790-1816», en Katz, Friedrich (comp.), Revuelta, rebelión y revolución. La lucha rural en México del siglo XVI al siglo XX, México, Ediciones Era, 2008, 187-222.

Terán, Marta: «El movimiento de los indios, de las castas y la plebe de Valladolid de Michoacán en el inicio de la guerra por la independencia. 1809-1810», en Terán, Marta y Serrano, José Antonio (eds.), Las guerras de independencia en la América Española, México, El Colegio de Michoacán-Instituto Nacional de Antropología e Historia-Universidad Michoacana de San Nicolás Hidalgo, 2002, 273-295. 
Tutino, John: «Buscando independencia popular. Conflictos sociales e insurgencia indígena en el Mezquital mexicano, 1800-1815», en Terán, Marta y Serrano, José Antonio (eds.), Las guerras de independencia en la América Española, México, El Colegio de Michoacán-Instituto Nacional de Antropología e Historia-Universidad Michoacana de San Nicolás Hidalgo, 2002, 295-322.

Van Young, Eric: La otra rebelión. La lucha por la independencia de México, 1810-1821, México, Fondo de Cultura Económica, 2006.

Villa-Señor y Sánchez, José Antonio: Theatro Americano: Descripción General de los Reynos, y Provincias de la Nueva-España, y sus jurisdicciones, 2, México, Talleres Editora Nacional S.A., 1952. 